\title{
Money wage rigidity, monopoly power and hysteresis
}

\author{
Alfonso Palacio-Vera* \\ Universidad Complutense de Madrid, Spain
}

\begin{abstract}
The literature that addresses the effects on the level of aggregate demand of changes in the degree of monopoly typically assumes away the existence of an "inflation barrier" and an inflationtargeting central bank. The presence of these two institutional factors entails that any aggregate demand change brought about by changes in the functional distribution of income will tend to be offset by changes in real interest rates. We postulate a simple macroeconomic model for a closed economy with a government sector and hypothesize that a change in the average mark up affects the inflation rate, the "inflation-barrier" and aggregate demand. The model allows for the analysis of the effects on the employment rate of demand and supply shocks when the economy exhibits asymmetric inflation dynamics (AID) and hysteresis effects. Among other results we find that, if the economy exhibits AID and hysteresis, the effect on the employment rate of a change in the mark up is likely to be either ineffectual or counterproductive even if the associated demand shock is expansionary. We also show that an inadequate functional distribution of income may lead to the occurrence of an aggregate demand deficiency problem.
\end{abstract}

JEL Classification: B50, E12, E24, E50

Key words: Neutral interest rate, degree of monopoly, asymmetric inflation dynamics, zero lower bound, hysteresis, reversibility 
Documento de Trabajo 2008-002

"MONEY WAGE RIGIDITY, MONOPOLY POWER AND HYSTERESIS"

Alfonso PALACIO-VERA 
Esta publicación de Documentos de Trabajo pretende ser cauce de expresión y comunicación de los resultados de los proyectos de investigación que se llevan a cabo en la Facultad de Ciencias Económicas y Empresariales de la Universidad Complutense de Madrid.

Los Documentos de Trabajo se distribuyen gratuitamente a las Universidades e Instituciones de Investigación que lo solicitan. No obstante, están disponibles en texto completo a través de Internet: 
MONEY WAGE RIGIDITY, MONOPOLY

POWER AND HYSTERESIS

Alfonso PALACIO-VERA 


\section{Money wage rigidity, monopoly power and hysteresis}

\section{1.- Introduction}

An extensive theoretical and empirical literature in the heterodox economics tradition (HET hereafter) has addressed the impact on unemployment of changes in the functional distribution of income stemming from a change in the average degree of monopoly. ${ }^{1}$ In this literature, it is commonly postulated that an increase in the wage (profit) share in national income has contradictory effects on the different subaggregates of aggregate demand so its net effect is ambiguous. In general, this literature takes for granted that the level of economic activity is demand-determined in the short and the long run and thus ignores (i) the existence of a short-term "inflation barrier" determined by the conflict over income distribution between workers and firms, (ii) the impact of changes in the degree of monopoly as captured by changes in the average mark up on both the "inflation barrier" and the inflation rate in the short run, and (iii) that a salient feature of the institutional framework that characterizes most present-day economies is that central banks (CBs hereafter) set short-term nominal interest rates in order to achieve an inflation target. When taking all these features into account, it seems to us that it is hardly realistic to study the implications of changes in the degree of monopoly by leaving aside their impact on the supply-side of the economy and, due to their shortrun impact on the inflation rate, on real interest rates.

In the last decade or so we have witnessed the emergence of the so-called "New Consensus" on Macroeconomics (NC hereafter) ${ }^{2}$. The NC has been summarised in terms of a simple model with three equations: (i) an aggregate demand equation with the output-gap typically determined by past and expected future output-gap and the exante real interest rate, (ii) a short-run Phillips curve with inflation typically based on current output-gap and past and future inflation and (iii) a monetary policy rule of the Taylor's rule form that endogenises the setting of interest rates by the CB. The NC strongly suggests that there is no long-run trade-off between inflation and unemployment and that, as a result of it, inflation can be conveniently tamed though interest rate policy using aggregate demand deflation. Unlike the literature referred to above, the NC tends to ignore the impact of the functional income distribution on unemployment. There are (at least) two reasons for this. First and foremost, mainstream economics has traditionally skipped the analysis of a class-ridden socio-economic structure and, hence, the possibility that different social groups have different sources of income and different propensities to spend out of income. Arguably, this is related to the adoption of "methodological individualism" as a key principle of the Neoclassical Research Programme. Second, proponents of the NC approach tend to view the level of economic activity as hovering in the short run around a supply-determined equilibrium that is assumed to be largely independent of the level and time path of aggregate demand. This supply-determined equilibrium is referred to as the "natural rate of unemployment" or as the NAIRU, the acronym for "non-accelerating inflation rate of unemployment". This study represents an attempt to construct a general framework that encompasses both the HET and the $\mathrm{NC}$ as particular cases and to explore its implications for unemployment. To be sure, it incorporates some features of the HET by assuming there are different social groups with different sources of income (i.e., wages and profits) and hysteresis effects, and by adopting Keynesian liquidity preference (LP hereafter) theory. Likewise, it incorporates some key features of the $\mathrm{NC}$ as the existence of an "inflation barrier" and an inflation-targeting CB that sets interest rates. 
Economists have recently used the concept of hysteresis especially in the field of unemployment theory since its properties seem to fit well the unemployment dynamics of the last three decades, especially in Western Europe. For instance, Ball (1999) suggests that passive macroeconomic policies are largely to blame for the observed rise in unemployment in several OECD countries since 1985. In countries where policy shifted toward expansion after tight policy had disinflated the economy, unemployment rose only temporarily. By contrast, in those countries where policy remained tight unemployment rose permanently (Ball, 1999, p. 190). Ball blames for this outcome to the presence of hysteresis effects that operated through the impact on "equilibrium unemployment" of the fraction of the long-term unemployed. Despite an initial wave of studies that lent empirical support to the notion of hysteresis (see the survey in Røed, 1997), the subsequent emergence of controversial evidence in the nineties, especially for North America, led to an apparent loss of interest in this concept. However, several recent contributions have reopened the debate on the notion of hysteresis. For instance, León-Ledesma (2002) finds strong support for this hypothesis for the EU countries. Likewise, Logeay and Tober (2006) find strong support for the existence of hysteresis in the Euro Area.

There is now a strong body of evidence indicating the presence of "downward money wage rigidity" (hereafter DMWR) across a wide spectrum of countries (see Lebow et al., 2003, Akerlof, 2007, Holden, 2004 and Holden and Wulfsberg, 2008). Several explanations have been put forward for the existence of such rigidities, such as fairness and social norms (Bewley, 1999, and Akerlof, 2007) or labour market institutions (Holden, 2004). The combination of these factors implies that these nominal rigidities could persist for a long time even in a low inflation environment. Indeed, empirical studies for European countries find that DMWR persist during low inflation periods (Agell and Lundburg, 2003 and Fehr and Lorenz, 2005). Similarly, the recent Japanese experience shows that, despite the presence of a large negative output-gap for most of the period 1991-2002, inflation turned negative in the second half of the 1990s but, after 1998, core inflation remained stable at moderately negative levels reaching its trough at -0.79 percent in 2002 (De Veirman, 2007). ${ }^{3}$ The presence of DMWR and the recent Japanese experience suggest that, when the output-gap becomes negative and inflation is low or negative, the former is likely to manifest itself in the existence of "asymmetric inflation dynamics" (AID hereafter) in the sense that inflation decreases more sluggishly when the output-gap is negative and inflation is relatively low than it increases when the output-gap is positive. ${ }^{4}$

According to us, the main contributions of this study are the following. First, we find that, in an economy characterized by the presence of an inflation-targeting CB and a short-run "inflation barrier" that exhibits hysteresis effects, a change in the average mark up affects the employment rate in the long run through the initial impact on the "inflation barrier" and the inflation rate. In particular, an increase in the mark up leads to a long-run decrease in the employment rate and vice-versa. Second, we show that, when the economy also exhibits AID, a change in the average mark up is less effective and may lead to a long-run fall in the employment rate even when it contracts. This is because the long-run impact on the employment rate of the demand shock, even when it is expansionary, is adverse owing to the presence of AID. Therefore, in this second scenario, a contraction in the average mark up only brings about a long-run increase in the employment rate if the net long-run adverse effect of the demand shock (even when the latter is expansionary) is more than offset by the sum of the favourable effects stemming from the initial fall in the inflation rate and the attenuation of the "inflation barrier". More generally, we show that the joint presence of hysteresis effects and AID 
in the economy (i) helps attenuate macroeconomic volatility and (ii) blocks off the "reversibility" property typically exhibited by zero/unit root systems. Third, we find that, in the above scenario, whether the economy exhibits a "wage-led" or a "profit-led" macroeconomic regime is largely irrelevant for macroeconomic performance as long as the economy does not exhibit an "aggregate demand deficiency". Fourth, we show that, despite the previous results, a change in the functional distribution of income may nevertheless impinge favourably on macroeconomic performance if it raises the steady growth neutral interest rate since this reduces the likelihood that an aggregate demand deficiency occurs. Lastly, we identify a Keynesian and a Neoclassical regime according to whether an increase in the actual inflation rate leads to an increase (Keynesian) or to a decrease (Neoclassical) in the neutral interest rate and show that the regime the economy exhibits affects the stability conditions of the economy.

The study continues as follows. The following section proposes a definition of an aggregate demand deficiency problem, reviews the $\mathrm{NC}$ approach and compares its predictions to those of LP theory. We then present a simple model for a closed economy with a government sector. We work out its steady-growth properties and short-run behaviour. The analysis of the dynamics associated to demand and inflation shocks follows and the final section summarizes and concludes.

\section{2.- Aggregate demand deficiencies and the New Consensus approach}

It is well-known that short-term nominal interest rates are subject to a zero lower bound constraint. This feature was termed by Kaldor (1939) the 'great constitutional weakness' of monetary policy because it prevents the short-term nominal interest rate from operating equally freely in both directions. In the context of this study, the relevance of the zero lower bound constraint stems from the fact that, if the $\mathrm{CB}$ finetunes the economy through changes in interest rates, then an inadequate functional distribution of income may bring about an aggregate demand deficiency problem so that the functional distribution of income will affect macroeconomic performance. We define the former as a scenario where, with nominal interest rates at or near zero, the CB is unable to push down real interest rates far enough so as to induce a level of output equal to potential output. ${ }^{5}$

We define the neutral interest rate $r^{n}$ as the long-term real interest rate which is neutral with respect to the inflation rate and tends neither to raise nor to lower it in the absence of transitory supply shocks ${ }^{6}$. In a closed economy with a government sector, there will be an aggregate demand deficiency when planned aggregate saving exceeds the sum of planned private investment plus the government budget deficit at the employment rate consistent with constant inflation even at a zero short-term nominal interest rate. If we denote by $\omega$ the minimum (ex-ante) real interest rate that a $\mathrm{CB}$ can set then the economy will exhibit an aggregate demand deficiency problem if:

$$
r^{n} \prec \omega
$$

If we think of $r$ as a short-term real interest rate then the minimum (short-term) nominal interest rate that the $\mathrm{CB}$ can set is zero. By contrast, if we think of $r$ as a longterm real interest rate, the minimum (long-term) nominal interest rate that the $\mathrm{CB}$ can set is positive because lenders will normally require a (time-varying) term/risk premium $\mu \succ 0$ to grant credit or purchase long-dated securities. ${ }^{7}$ In turn, the size of the term/risk premium will depend positively on the degree of LP. If we assume, for the sake of simplicity, that the expected rate of inflation $\pi^{e}$ equals the current inflation rate $\pi$ we have: 


$$
\omega=\mu-\pi^{e}=\mu-\pi
$$

Therefore, we say that an economy exhibits an aggregate demand deficiency if:

$$
r^{n}+\pi \prec \mu
$$

Expression (3) tells us that the lower are $r^{n}$ and $\pi$, and the higher is $\mu$ the more likely it is that an economy that is hit by a shock that pushes either $\pi$ or $r^{n}$ (or both) down will exhibit an aggregate demand deficiency. If this is the case, then the current level of output will be lower than potential output and inflation will tend to fall.

A number of mainstream economists have recently evaluated the likelihood of economies exhibiting an aggregate demand deficiency and the policy options that may remove this constraint should it be necessary. A summary of the former is in Blinder (2000) and an evaluation of the different proposals is in Bernanke and Reinhart (2004). There seems to be an emerging consensus on the view that the existence of a zero lower bound constraint on nominal interest rates will lead to a moderate deterioration in macroeconomic volatility as the inflation target approaches zero so it represents a constraint on how monetary policy operates in a low inflation environment (Fuhrer and Madigan, 1997; Reifschneider and Williams, 2000). One aspect these studies address is the possibility that an economy enters a deflationary episode once the zero lower bound constraint binds. The verdict is "that such episodes are fairly rare, even in a lowinflation environment - about once every hundred years if the target rate of inflation is around zero, given the sort of shocks that have characterized the U.S. economy over the past thirty years' (Reifschneider and Williams, 2000, p. 962). Thus, the conclusion is that a deflationary episode may come about only in the wake of unusually large shocks. The studies also recommend setting a low but positive inflation target (preferably 2 per cent). Conversely, there is no consensus as to whether unconventional monetary policy options can take the economy out of a deflationary episode should it be necessary. Yet, as argued in Reifschneider and Williams (2000, p. 943), a summary of the debate is that 'the likely effectiveness of such actions is unclear from a theoretical perspective, and they have never been put to a definitive test'. Only discretionary fiscal policy is viewed as a reliable weapon once the zero lower bound constraint binds (Kuttner and Posen, 2001, pp. 124-140). In this respect, the words of Kazuo Ueda at the 1999 JMCB Conference serve to summarize the conventional wisdom on this subject: 'Don't put yourself in the position of zero interest rates. You'll have to face a lot of difficulties. I can tell you it will be a lot more painful than you can possibly imagine' (Ueda, 2000, p.1109).

The predominant wisdom in the mainstream literature that a deflationary episode may only occur in the wake of unusually large shocks appears to be consistent with the theoretical predictions of the NC approach. In the influential study by Woodford (2003) which, for the purposes of this study, will be taken as the canonical version of the NC approach, he develops a neo-Wicksellian framework based on explicit optimizing foundations where the deviation of the natural interest rate from its steady growth value is a stochastic process determined by a range of demand and supply shocks (Woodford, 2003, pp. 249-51). In his model, demand shocks include fiscal policy, investment and impatience shocks. The latter modify the rate of time preference of the representative household. Supply shocks consist of productivity shocks to the production function of the firms, shocks to the disutility-of-labour function and changes in the amount of capital. He concludes that real interest rates must increase in response to temporary increases in government purchases or in the impatience of households to consume and decrease in response to temporary increases in productivity or in the willingness of households to supply labor' (Woodford, 2003, p. 250). He defines the natural interest 
rate as 'the equilibrium real rate of return in the case of fully flexible prices' (Woodford, 2003 , p. 248). Crucially, he admits the possibility that a range of transitory shocks may make the natural interest rate negative, albeit he suggests that this will be a transitory scenario:

'The present theory allows for variation over time in the natural rate for a variety of reasons, and there is no reason why it should not sometimes be negative. (The model does imply a positive average level of the natural rate, determined by the rate of time preference of the representative household)' (Woodford, 2003, p. 251).

We may extrapolate Woodford's results to a growing economy by relying on optimal growth theory. According to it, the optimality condition for saving yields the following "balanced growth" condition:

$$
r^{*}=\frac{a}{\sigma}+n+\vartheta
$$

where $r^{*}$ is the natural interest rate in steady-growth, $a$ is the rate of labour-augmenting technological change, $n$ is the rate of population growth, $\sigma$ is the inter-temporal elasticity of substitution in consumption and $\vartheta$ is the rate of time preference of the representative household. ${ }^{8} a$ and $n$ are positive in a growing economy. Hence, the natural interest rate will be positive in steady growth and its lower bound will be $\vartheta$. Finally, in the stationary state we have that $a=n=0$ and, hence, $r^{*}=\vartheta$.

Several comments are in order. First, the literature seems to conflate different meanings of the notion of a natural interest rate. ${ }^{9}$ This problem was recognized long time ago by Myrdal (1939) who noted that monetary equilibrium in Wicksell's theory entails that the natural rate of interest must (i) equal the marginal productivity of real capital, (ii) equate the supply and the demand for savings at full employment and, (iii) guarantee a stable price level. Only the third meaning is compatible with our previous definition of the neutral interest rate albeit it needs to be adapted to a modern setting where it is the inflation rate and not the price level that is stable in the long run. ${ }^{10}$ This is because (i) we will assume that the economy operates in the long run at an employment rate that is equal (or lower) than the rate of employment compatible with a constant inflation rate and this, in turn, corresponds to an employment rate that falls short of full employment and (ii) the notion of the marginal productivity of capital is flawed (see Harcourt, 1969). Furthermore, there is nothing natural about the natural interest rate since it depends, inter alia, on the government budget balance and so we think that the term "neutral" is preferable. Be that as it may, the role of the natural interest rate in the $\mathrm{NC}$ approach is equivalent to the role of the neutral interest rate as defined above, namely, it is the real interest rate that renders the inflation rate constant in the absence of transitory supply shocks or as Woodford (2003, p. 248) notes 'the natural rate of interest is just the real rate of interest required to keep aggregate demand equal at all times to the natural rate of output'.

Second, Woodford's assumption that the average value of the natural interest rate is positive implies that the natural interest rate returns in the long-run to a positive gravitation centre provided prices are fully flexible. The process whereby this occurs is not discussed in Woodford (2003). Presumably, the argument is that, in a hypothetical situation where actual output equals potential output and, in the absence of shocks, economic agents will increase their saving rate whenever the actual real interest rate is above their rate of time preference and vice-versa so that, in equilibrium, the former will necessarily equal the latter. The adjustment process can be put forward as follows. Let us assume that the economy initially exhibits an aggregate demand deficiency problem 
so that the actual real interest rate exceeds the natural interest rate. If so, inflation will start to fall. Since the actual real interest rate (which may be negative) falls short of the average rate of time preference (which is positive), households will increase their consumption so the natural interest rate will increase. This process will continue as long as the actual real interest rate falls short of the rate of time preference. Eventually, the actual real interest rate and the natural interest rate will converge to the average rate of time preference and the economy will reach equilibrium. However, this story faces (at least) one problem; as recognized by most proponents of the NC approach, the economy may end up caught in a deflationary spiral if the initial decrease in the inflation rate endogenously raises the level of the real rate so as to cause aggregate demand to weaken and push inflation down more, thereby raising the real interest rate even further. Therefore, if a deflationary spiral is to be avoided, proponents of the NC approach need to assume that the adjustment process described above will not be short-circuited by the adverse effect upon aggregate demand of a rising actual real interest rate. However, the possibility that, under certain circumstances, a deflationary spiral may set off is readily recognized by proponents of the NC approach so the main theme of our critique to this story needs to rely on a different argument.

We believe that the specific PK critique of the adjustment process described above is that the latter may be short-circuited for reasons other than a deflationary spiral. PK theorists insist that individuals make decisions in an environment intrinsically characterized by "fundamental uncertainty" where probability distributions cannot be the basis for comprehending real world behaviour because they simply do not know all the possible future outcomes and, hence, they cannot attach a probability to them (Davidson, 1991). Consequently, individuals' decisions concerning saving, investment and the allocation of wealth among alternative assets will tend to be dominated by LP considerations. To see this, we may note that, in PK theory, the real interest rate is the reward obtained for parting with liquidity rather than (as in neoclassical theory) the reward for postponing consumption. In turn, the degree of LP is positively related to the degree of uncertainty (Keynes, 1937, p. 216). PK theorists thus identify the notion of LP with an environment of "fundamental uncertainty" where the degree of LP is inversely related to the degree of confidence. Crucially, they claim that, if investors' expectations are such that they expect that the holding of real or financial assets other than money will make them incur in large capital losses then, there is a rationale for placing wealth in a liquid asset or, alternatively, to use the former to repay outstanding debt. If so, they will postpone consumption plans and increase the liquidity of portfolios. Furthermore, PK theorists insist that reduced LP accompanies conditions which are conducive to increases in economic activity and vice-versa. Thus, within a generalized LP theory, a decrease in aggregate demand may be the result of a high degree of LP associated to pessimistic expectations and vice-versa or:

'A world of ultimate liquidity preference is a world where firms would refuse to produce for fear of indebtedness, where banks would refuse to lend for fear of loan defaults, and where consumers would refuse to spend for fear of unemployment' (Lavoie, 1996, p. 292).

The existence of "fundamental uncertainty" will thus tend to dominate saving and investment decisions even if we assume that households exhibit a subjective rate of time preference. In particular, if households are pessimistic about the future, they may well decide to increase their saving rate even if the actual real interest rate falls short of their rate of time preference thus reducing aggregate demand. In addition, an increase in 
the degree of LP of banks will make them reluctant to grant credit and this will also tend to depress aggregate demand. More generally, the adjustment process posited above only applies to a situation where uncertainty is akin to the notion of probabilistic risk. For the purposes of this study, the crucial implication is that the steady growth neutral interest rate may be negative and will not possess a (positive) centre of gravitation as envisaged in the $\mathrm{NC}$ approach.

Lastly, proponents of the $\mathrm{NC}$ approach apparently argue that an aggregate demand deficiency problem may only come about when the neutral interest rate is negative. However, expression (3) reflects that an aggregate demand deficiency problem may also occur in a situation where both the neutral interest rate and the inflation rate are positive. This may be the case if the term/risk premium on loan rates becomes large enough so as to satisfy condition (3). The importance of the term/risk premium is recognized in Blinder (2006, pp. 47-48) when he notes that 'long rates are terrible (and biased) predictors of future short rates... Just why this is so remains a major intellectual puzzle'. Yet, he does not link the size of the term/risk premium to the degree of LP. Likewise, Woodford (2003, p. 244) notes that 'it is a long-term real rate of interest rather than a short rate, that determines aggregate demand in this model' and he refers to agents' expectations about future short-term real interest rates as an important determinant of aggregate demand but he does not mention the possibility that the term/risk premium on loan rates may vary as a result of changes in the degree of LP.

\section{3.- The model}

We now present the model we will utilize hereafter to analyze a variety of issues related to the impact on the level of economic activity of demand and supply shocks when the CB implements a conventional IT strategy. The exposition is divided into five subsections. The first three subsections contain the different building blocks of the model, the fourth subsection presents the steady-growth analysis and the final one describes the behaviour of the economy in the short run.

\section{1.- The supply side}

Let us consider a one-sector economy with two inputs, labour and capital, and assume that (i) there is a large number of identical firms and (ii) they all utilize the same technology. If we aggregate across all firms in the economy we may define potential output $\bar{Y}$ as:

$$
\bar{Y}=\lambda \cdot \bar{N} \leq v \cdot K
$$

where $\bar{N}$ is the level of employment that keeps inflation constant in the absence of transitory supply shocks, $K$ is the capital stock, and $\lambda$ and $v$ are respectively the productivity of labour and capital when the factors are fully utilized. The current rate of capacity utilization is:

$$
u=\frac{Y}{v \cdot K} \leq 1
$$

where $Y$ is the actual rate of output. Post Keynesians like Rowthorn (1977) and Sawyer (1982) postulate the existence of a employment rate compatible with constant inflation in the short run (hereafter CIER) which results from the conflicting income claims of workers and firms. ${ }^{11}$ Thus, the CIER represents an "inflation barrier" albeit it may be affected by the level and time path of aggregate demand in the long run if, for instance, hysteresis effects are present. Be that as it may, the presence of an "inflation barrier" entails that the $\mathrm{CB}$ will seek to adjust interest rates to affect the level of economic 
activity so as to balance off the income claims. Therefore, the rate of capacity utilization when $Y=\bar{Y}$ is:

$$
\bar{u}=\frac{\bar{Y}}{v K}=\frac{\lambda}{v} \cdot \frac{\bar{N}}{K}=\left(\frac{\lambda}{v}\right) \cdot\left(\frac{\bar{e} \cdot L}{K}\right) \leq 1
$$

where we denote by $\bar{u}$ the "constant inflation capacity utilization" (CICU hereafter), by $\bar{e}$ the CIER, by $L$ the labour force and where $\bar{N}=\bar{e}(m) \cdot L .^{12}$

Let us now assume there is no overhead labour and firms are fully integrated, producing all the materials required for their final output so that prime costs are made up only of labour costs. If we also assume that firms practise mark up pricing, then the real (product) wage is determined by the firms' profit-maximization objectives:

$$
\frac{w}{p}=\frac{\lambda}{m}
$$

where $w$ is the money wage, $p$ is the price level and $m \succ 1$ is one plus the average mark up set by firms over prime costs,. Furthermore, in the absence of overhead labour, the profit share on national income $\rho$ can be expressed as (Asimakopulos, 1975):

$$
\rho=\left(\frac{m-1}{m}\right)=\left(1-\frac{w / p}{\lambda}\right)
$$

where $\partial \rho / \partial m=1 / m^{2} \succ 0$. Hence, $\rho$ depends in a straightforward manner on the mark up over prime costs used for pricing purposes. Importantly, an increase in $m$ - and hence in $\rho$ - reduces the CIER and vice-versa so $\bar{e}_{m} \prec 0$ where the subscript denotes a partial derivative. This stems from the fact that, as $m$ rises, employees need to accept a lower real (product) wage relative to average labour productivity if the rate of inflation is to be kept constant. ${ }^{13}$ If we assume that workers' bargaining power and/or propensity to shirk depends inversely on the unemployment rate, then a higher $m$ will lead to a higher unemployment rate in the long run. Hence, expression (6) can be re-expressed as:

$$
\bar{u}(m)=\left(\frac{\bar{e}(m)}{v}\right) \cdot\left(\frac{\lambda \cdot L}{K}\right) \leq 1
$$

Next, as claimed in Palley (1994) and Akerlof et al. (1996), the lower the inflation rate, the larger is the fraction of firms which can only implement real wage cuts through a reduction in the money wage they pay to their workers. According to them, in the presence of DMWR a lower inflation rate thus implies that a larger fraction of firms is forced to pay real wages exceeding the wage which they deem optimal. In the model of Akerlof et al. (1996), this increases the long-run sustainable level of unemployment and provides the rationale for the existence of a "grease" effect of inflation on the labour market whereby a marginal rise in the inflation rate may reduce the equilibrium rate of unemployment when inflation is low. Yet, if firms follow a mark up pricing strategy and total average costs are roughly constant for a wide range of rates of capacity utilization the presence of DMWR is more likely to show up in a diminished tendency for the rate of inflation to fall for a given (negative) output-gap as inflation falls below a certain threshold. ${ }^{14}$ If we add the proposition that, as observed in the recent Japanese recession, the change in the inflation rate becomes nil (when the outputgap is negative) as the inflation rate gets below a negative level given by $\left(\phi_{\pi} \pi^{C R}-\phi_{U}\right) / \phi_{\pi}$, we obtain the expression that captures the AID:

$$
\dot{\pi}=\left\{\begin{array}{lll}
\phi_{U}(u-\bar{u}(m))+\varepsilon_{\pi} & \text { if } & u \succ \bar{u}(m) \\
\phi_{L}(u-\bar{u}(m))+\varepsilon_{\pi} & \text { if } & u \prec \bar{u}(m)
\end{array}\right.
$$


where $\phi_{L}=\left\{\begin{array}{ccc}\phi_{U} & \text { if } & \pi \geq \pi^{C R} \\ \phi_{U}+\phi_{\pi}\left(\pi-\pi^{C R}\right) & \text { if } & \frac{\phi_{\pi} \pi^{C R}-\phi_{U}}{\phi_{\pi}} \prec \pi \prec \pi^{C R} \\ 0 & \text { if } & \pi \leq \frac{\phi_{\pi} \pi^{C R}-\phi_{U}}{\phi_{\pi}}\end{array} \quad \phi_{U}, \phi_{\pi} \succ 0\right.$

where $\varepsilon_{\pi}$ is a variable that captures transitory cost-push shocks and $\pi^{C R} \succ 0$ represents a (positive) inflation rate below which the downward adjustment of the rate of growth of money wages, and hence of the inflation rate, becomes slower and eventually comes to a halt. ${ }^{15}$ The basic proposition is that as the inflation rate decreases and falls below $\pi^{C R}$, some firms will need to cut money wages if their product prices are to decrease. In turn, the proportion of firms that is subject to his constraint will increase as the inflation rate decreases further. In Akerlof et al. (1996), $\pi^{C R}$ was estimated to be about 3 percent for the U.S. economy.

Equation (10) also tells us that the inflation rate adjusts differently depending on: (i) whether actual capacity utilization is higher or lower than the CICU and (ii) whether the inflation rate is equal, higher or lower than $\pi^{C R}$. As such, $\phi_{L}$ may take on three different values. For instance, if the current inflation rate is equal or higher than $\pi^{C R}$ then inflation dynamics will be symmetric in the sense that the change in the rate of inflation will solely depend on the absolute value of the output-gap. If the inflation rate is lower than $\pi^{C R}$ but higher than the lower threshold $\left(\phi_{\pi} \pi^{C R}-\phi_{U}\right) / \phi_{\pi}$ then the adjustment of the inflation rate will be asymmetric since the change in the inflation rate will depend both on the size and sign of the output-gap, that is, a positive output-gap will tend to engender a larger (absolute) change in the inflation rate than a negative one of similar size. The asymmetry will be larger the closer the inflation rate is to the lower threshold. Finally, inflation will stop decreasing when it becomes equal to the former.

\section{2.- Hysteresis}

In economics, the notion of hysteresis has generated a number of different formal characterizations (Amable et al., 1995). Hysteresis is typically associated with dynamic linear models characterized by zero root systems for continuous time models or by unit root systems for models in discrete time (Giavazzi and Wyplosz, 1985). In such systems there is a continuum of equilibria and the final equilibrium reached, selected from within the continuum, depends on the particular features of the system. In a deterministic setting the final equilibrium point depends on the initial conditions of the state variables as well as on the parameters describing the speed of adjustment. In a stochastic setting, the position of the system is determined by the chronicle of exogenous shocks owing to the fact that the latter cumulate forever without progressively vanishing. According to Dutt (1997, p. 240) 'systems of this kind can be called path-dependent systems' since, in these models, history plays a key role in the sense that the starting point and the time path of the economy determine the final outcome.

An important property of these systems is that an initial shock followed by a second one of the same magnitude but opposite sign drives the system back to its initial position. This "reversibility" property has a crucial implication. If exogenous shocks are generated by a symmetric probability distribution, then negative and positive shocks 
cancel each other out in the long run. Hence, with zero/unit root systems, any long-run permanent effect on unemployment can solely be caused by (i) exogenous shocks that are generated by an asymmetric probability distribution, (ii) an asymmetric adjustment of prices to shocks of opposite sign or (iii) an asymmetric response to shocks by policy makers (Fontana and Palacio-Vera, 2007). In this study we will focus on the second of these possibilities. This "reversibility" feature of zero/unit root systems has encouraged some scholars to investigate the properties of systems showing hysteresis. Drawing on the work of the Russian mathematician Mark Krasnosel'skii, it has been argued that a system is hysteretic if it exhibits "remanence", i.e., when the value of the output is permanently affected by an appropriate temporary change in the value of the input (Amable et al., 1995). The crucial point is that, in hysteretic systems, a relevant exogenous force modifying the value of a given parameter $\lambda$ entails a change in the system dynamics. For instance, the structural modification may move the system out of the initial equilibrium and toward a new equilibrium. By altering the exogenous force such as to bring parameter $\lambda$ back to the initial value, a structural deformation of equal magnitude but opposite sign is produced. However, and this is a crucial difference with the case of zero/unit root (linear) systems, the system does not return to the original equilibrium point. In other words, the temporary change in the value of $\lambda$ has produced a "remanent" effect on the final state of the system (Amable et al., 1995, p. 172; see also Dutt, 1997). As we show below, the presence of AID may render a zero/unit root system hysteretic and makes it exhibit "remanence". However, instead of relying on an abstract structural modification of the system, our approach builds on Setterfield (1998) by (realistically) assuming the presence of asymmetries in the adjustment of inflation.

Following a suggestion by Hargreaves Heap (1980), we model the dynamics of the CIER as:

$$
\dot{\bar{e}}=\zeta(e-\bar{e}) \quad \zeta \geq 0
$$

where the overdot denotes a time derivative, $\zeta \succ 0$ measures the speed of adjustment of the CIER whenever it exhibits hysteresis effects and the case $\zeta=0$ corresponds to the case without hysteresis. Hence, we view the presence of hysteresis effects in the CIER as making it depend on the time path of the actual employment rate so that an increase in the latter tends to raise the CIER up and vice-versa.

\section{3.- The demand side}

The equilibrium condition in the goods markets for a closed economy with a government sector when current output is equal to potential output is:

$$
s\left(r^{n}, z\right) \cdot \bar{Y}=I+P S B R
$$

where $s$ is the saving rate, $I$ is (gross) investment, PSBR is the public sector borrowing requirements, and $z$ is a vector of variables to be filled below. The real interest rate in (12) is the neutral interest rate which we define as the real interest rate that (in a closed economy) makes planned saving at potential output equal to the sum of planned gross investment and the PSBR. It is better thought of as a long-term interest rate (Fuhrer and Madigan, 1997). We denote by $\bar{Y}$ the level of potential output or the level of output that keeps inflation constant in a given period in the absence of transitory supply shocks so that inflation will increase (decrease) when $r \prec r^{n} \quad\left(r \succ r^{n}\right)$. If we divide (12) through by the capital stock $K$, denote the net investment rate by $g$, the rate of depreciation of capital by $\psi$ and make $b=P S B R / Y$, we can rewrite (12) as:

$$
(s-b) \cdot \bar{u}(m) \cdot v=g+\psi
$$

The "natural" rate of growth is: 


$$
g_{n}=l+a
$$

where $l$ and $a$ are respectively the growth rate of labour force $L$ and labour productivity $\lambda$. We now turn our attention to functions $s$ and $g$. We assume that the saving rate $s$ is a function of the rate of inflation $\pi$, the rate of growth of output $\hat{y}$, the mark up $m$, the real interest rate $r$ and a measure of shocks $\varepsilon_{s}$ or:

$$
s=s\left(\pi, \hat{y}, r, m, \varepsilon_{s}\right)
$$

where $s_{\pi}$ cannot be signed a priori, $s_{\hat{y}} \succ 0, s_{r} \succ 0, s_{m} \succ 0, \varepsilon_{s}$ is a stochastic variable denoting shocks to the saving rate, and the subscripts denote the partial derivatives of $s$. The positive sign of derivative $s_{\hat{y}}$ stems from Marglin's "disequilibrium hypothesis" (Marglin, 1984), according to which, the saving rate increases when income rises faster than households can adapt their spending habits whereas the opposite occurs when income falls faster than households can rein in their spending. The positive sign of $s_{r}$ is here attributed to the presence of distribution effects. If we assume (realistically) that the average propensity to consume of net debtors is higher than that of net creditors, then a rise in the real interest rate will redistribute income away from net debtors and towards net creditors thereby raising the aggregate saving rate. The positive sign of $s_{m}$ stems from the fact that the average propensity to save out of profit income is typically higher than the propensity to save out of wage income owing to the fact that (i) firms retain a large fraction of their after-tax net profits in order to fund investment spending and (ii) ownership of corporate stock tends to be concentrated in the upper income brackets which have higher personal saving rates. Hence, $s$ rises with $m$ and, hence with $\rho$, and vice-versa.

The sign of $s_{\pi}$ is ambiguous. Neoclassical economists tend to assume that $s_{\pi} \succ 0$ due to the operation of a dynamic version of the "real balance" effect called the inflation tax whereby increases (decreases) in inflation tend to reduce (increase) the holdings of real balances by economic agents' thus making them, in turn, increase (reduce) their saving rate in order to restore the optimum amount of real balances. The empirical relevance of the "real balance" effect, however, has been criticized by some mainstream economists. ${ }^{16}$ By contrast, the case $s_{\pi} \prec 0$ is advocated by Keynesians who, taking inspiration in chapter 19 of Keynes' General Theory (Keynes, 1936), emphasize the presence of "inside debt" effects which depress private spending when the price level falls, that is, when inflation becomes negative. However, if the case $s_{\pi} \prec 0$ is to be sound, this argument must apply also to the case when the inflation rate decreases but remains positive.

The argument can be explained as follows. Pollin (1985) shows that the stability of the total outstanding debt ratio $S_{t}=q_{t}(1+\hat{Y}) / \hat{Y}$ of the U.S. economy's non-financial sectors has displayed essentially no trend throughout the post-World War II period despite a rising marginal propensity of the aggregate non-financial sector to issue net new debt $q_{t}$. He argues that, in an inflationary environment, the nominal value of the debt stock remains fixed while the rate of growth of nominal GNP $\hat{Y}$ rises, so that $S_{t}$ is biased downwards. With $q_{t}$, current-period flow values are in both numerator and denominator, and thus the impact of inflation on the ratio is neutral. Because of this asymmetry, a rising $q_{t}$ may not engender increases in debt burdens in an inflationary environment. However, for a given $q_{t}$, a fall in the rate of inflation will increase net borrowers' real debt burden and vice-versa. In the case of net borrower households, the reduction in the inflation rate will make them curtail consumption demand. Presumably, 
this will be coupled by a rise in net lenders' real financial wealth and, hence, by an increase in their consumption. Yet, the marginal propensity to consume out of wealth of net borrowers is higher than that of net lenders' so that aggregate consumption will fall when inflation falls and vice-versa so that $s_{\pi} \prec 0$.

Next, let's assume that firms have a desired rate of capacity utilization $u^{*} \prec 1$ so they expand actual capacity when $u \succ u^{*}$ and scale investment down when $u \prec u^{*}{ }^{17} \mathrm{~A}$ justification for this assumption is that firms operating in imperfect markets keep some capacity idle in order to respond rapidly to unanticipated surges in demand and to deter the potential entry of rivals in the industry (Spence, 1977). Following Skott (1989), we also assume that $u^{*}=u^{*}(m)$ where $u_{m}^{*} \prec 0$ is the partial derivative of $u^{*}$ with respect to $m$. The rationale for $u_{m}^{*} \prec 0$ is that, for a given value of $u$, the profit rate on capital is a positive function of $\rho$ and, hence, of $m$. Since the risk of entry in the industry of new rivals increases as the profit rate rises, one way to deter them is to expand idle capacity. These assumptions can be captured by defining the rate of accumulation, $g$ as:

$$
g=v \cdot u \cdot f\left(u-u^{*}(m), \varepsilon_{g}\right)
$$

where $f_{u} \succ 0$ is inversely proportional to the length of the capital goods construction and delivery lags, $f(0)=\bar{f} \succ 0$ and $\varepsilon_{g}$ captures exogenous shocks hitting $g . \bar{f}$ is the ratio of net investment to output when $u=u^{*}$ and captures firms' average expected future rate of growth of demand. Therefore, it is affected by the state of long-term profit expectations. As for function $b$, we assume that:

$$
b=b\left(\hat{y}, r, \pi, \varepsilon_{b}\right)
$$

where the partial derivatives satisfy $b_{\hat{y}} \prec 0, b_{r} \succ 0, b_{\pi} \prec 0$ and where $\varepsilon_{b}$ are exogenous shocks affecting $b$. The negative sign of $b_{\hat{y}}$ is due to the working of fiscal automatic stabilizers so its (absolute) value measures the stabilizing power of (non-discretionary) fiscal policy. The sign of $b_{\pi}$ is here attributed to the fact that tax income bases may not be fully indexed so that a rise in the inflation rate will tend to reduce PSBR and viceversa. By contrast, the positive sign of $b_{r}$ captures the impact on PSBR of changes in the flow of interest payments due to the holders of government debt resulting from variations in real interest rates. Finally, $\varepsilon_{b}$ captures discretionary changes in the stance of fiscal policy. All this allows us to rewrite (13) as:

$$
s\left(\pi, \hat{y}, r^{n}, m, \varepsilon_{s}\right)-b\left(\hat{y}, r^{n}, \pi, \varepsilon_{b}\right)=f\left(\bar{u}(m)-u^{*}(m), \varepsilon_{g}\right)+\frac{\psi}{v \bar{u}(m)}
$$

where (18) represents the equilibrium condition in the goods market when $Y=\bar{Y}$.

\section{4.- Steady growth analysis}

Steady growth equilibrium corresponds to a period of sufficient length to enable all the variables in the economy to settle at constant rates in the absence of new shocks. In a hypothetical steady growth position we have that $\varepsilon_{s}=\varepsilon_{g}=\varepsilon_{b}=0, \hat{y}=g_{n}=g$, $u=\bar{u}=u^{*}$ and $\pi=\pi^{*}$ so the following two conditions must be satisfied:

and

$$
\begin{gathered}
v \cdot u^{*}(m) \cdot \bar{f}=g_{n}=\hat{y} \\
{\left[s\left(\pi^{*}, g_{n}, r^{*}, m\right)-b\left(\pi, g_{n}, r^{*}\right)\right] \cdot v \cdot u^{*}(m)=g_{n}+\psi}
\end{gathered}
$$

where $\pi^{*}$ is the inflation target of the CB. Equation (19) tells us that, in steady growth, the rate of accumulation must equal the "natural" rate of growth. Equation (20) is the 
counterpart to equation (18) for the steady growth equilibrium. In order to get a solution for the steady growth neutral interest rate $r^{*}$ we assume that functions $s$ and $b$ adopt a linear form or:

and

$$
\begin{gathered}
s=\bar{s}+s_{\hat{y}} \hat{y}+s_{\pi} \pi+s_{r} r+s_{m} m \\
b=\bar{b}+b_{\pi} \pi+b_{\hat{y}} \hat{y}+b_{r} r
\end{gathered}
$$

where $\bar{s}$ is a shift term determined by individuals' preferences, institutional factors and the degree of LP and $\bar{b}$ denotes the stance of fiscal policy. Substituting equations (21) and (22) into (20) and re-arranging we arrive at:

$$
r^{*}=\left[\frac{g_{n}+\psi}{v \cdot u^{*}(m)}-c_{1}-c_{\hat{y}} g_{n}-c_{\pi} \pi^{*}-s_{m} m\right] \frac{1}{c_{r}}
$$

where $c_{1}=\bar{s}-\bar{b}$ and $c_{\pi}=s_{\pi}-b_{\pi}$ cannot be signed a priori, $c_{\hat{y}}=s_{\hat{y}}-b_{\hat{y}} \succ 0$ and, for the sake of the argument, we assume that $c_{r}=s_{r}-b_{r} \succ 0$. Thus, $r^{*}$ depends inter alia on the "natural" rate of growth, the target rate of inflation, the aggregate saving rate, the stance of fiscal policy and the average mark up, and it can be interpreted as the real interest rate where 'all markets are in equilibrium and there is therefore no pressure for any resources to be redistributed or growth rates for any variables to change' (Archibald and Hunter, 2001, p. 20). Furthermore, $r^{*}$ also represents the real interest rate that is compatible with a neutral monetary policy in the long run and, therefore, it is akin to the neutral interest rate embedded in Taylor's rule (1993). The steady growth properties are:

$$
\begin{gathered}
\frac{\partial r^{*}}{\partial \pi^{*}}=\frac{-c_{\pi}}{c_{r}} \frac{\prec}{\succ} \\
\frac{\partial r^{*}}{\partial g_{n}}=\left(\frac{1}{v \cdot u^{*}}-c_{\hat{y}}\right) \cdot \frac{1}{c_{r}} \succ 0 \\
\frac{\partial r^{*}}{\partial \bar{b}}=-\frac{\partial r^{*}}{\partial \bar{s}}=\frac{1}{c_{r}} \succ 0 \\
\frac{\partial r^{*}}{\partial m}=\left(\frac{-\left(g_{n}+\psi\right) \cdot u_{m}^{*}}{v \cdot u^{*}(m)}-s_{m}\right) \cdot \frac{1}{c_{r}} \succ 0
\end{gathered}
$$

The ambiguous sign of (24) stems from the contradictory effects on aggregate demand of a change in the inflation rate. In principle, the sign of (25) is also ambiguous. However, it will be positive and close to unity for reasonable values of the parameters of the model. The positive sign of (26) reflects the fact that an increase in $s$ pushes $r^{*}$ down whereas an increase in $b$ raises aggregate demand and, hence, $r^{*}$. The ambiguous sign of (27) is here attributed to the fact that a change in $m$, and hence in $\rho$, affects the accumulation rate and the saving rate with contradictory effects on aggregate demand. Starting with Bhaduri and Marglin (1990), it is common usage to distinguish between a "wage-led" regime and a "profit-led" regime. In the former, an increase in the wage share leads to an increase in aggregate demand whereas, in the latter, an increase in the wage share reduces aggregate demand. Thus, we say that the economy is in a "wageled" regime if (27) is negative and in a "profit-led" regime if the opposite holds. In short, the functional distribution of income along with the inflation target, the aggregate saving rate, the "natural" growth rate and the fiscal policy stance determines $r$ and, hence, the likelihood of the occurrence of an aggregate demand deficiency problem (for a given degree of LP). An increase (decrease) in the mark up when the economy is "profit-led" ("wage-led") renders it less likely that the economy exhibits an aggregate demand deficiency and vice-versa. 


\section{5.- Short-run dynamics}

Steady growth equilibrium is only valid for explaining a hypothetical long-run scenario where the effects of shocks and lags have already worked themselves out. Admittedly, that scenario is unrealistic because an economy is constantly being shocked away from its steady growth equilibrium. Yet, the steady growth analysis provides an equilibrium outcome around which the economy hovers in the short run and may offer some insights. Next, we analyse the behaviour of the economy in the short run where the former is defined as the time it takes for the real interest rate to affect inflation. As before, we assume that the investment function $f$ adopts a linear form or:

$$
f\left(u-u^{*}(m), \varepsilon_{g}\right)=\bar{f}+f_{u} \cdot\left(u-u^{*}(m)\right)
$$

Substituting (28) into (18) and re-arranging we obtain the rate of growth of output $\hat{y}$ :

$$
\hat{y}=\frac{\bar{f}-c_{1}-s_{m} m-c_{\pi} \pi-c_{r} r+f_{u} \cdot\left(u-u^{*}(m)\right)}{c_{\hat{y}}}+\frac{\psi}{c_{\hat{y}} v u}
$$

A solution for $r^{n}$ can be obtained by setting $u=\bar{u}$ in (29) and rearranging:

$$
r^{n}=\frac{\bar{f}-c_{1}-s_{m} m-c_{\hat{y}} \hat{y}(m)-c_{\pi} \pi+f_{u} \cdot\left(\bar{u}(m)-u^{*}(m)\right)+\frac{\psi}{v \bar{u}(m)}}{c_{r}}
$$

so we have that:

$$
\begin{gathered}
\frac{\partial r^{n}}{\partial \bar{u}(m)}=\frac{c_{2}}{c_{r}} \frac{\prec}{\succ} 0 \\
\frac{\partial r^{n}}{\partial m}=\frac{c_{2}}{c_{r}} \cdot \bar{u}_{m} \frac{\prec}{\succ} 0
\end{gathered}
$$

where $c_{2}=\left(f_{u}-\frac{\psi}{v \bar{u}(m)^{2}}\right) \underset{\succ}{\succ} 0$ and $\bar{u}_{m} \prec 0$.

First, expression (31) highlights that a change in the CICU has an ambiguous impact upon $r^{n}$. This is because, an increase in the CICU and, hence, in $\bar{Y}$, brings about an increase in the flow of private saving at the higher level of output that may or may not be offset by the resulting higher rate of investment. If $c_{2} \prec 0$, the increase in the flow of saving will not be offset by the higher rate of investment and vice-versa. The standard textbook assumption that at the margin private saving is more responsive than investment to changes in capacity utilisation for making the Keynesian income adjustment process stable requires imposing a negative sign on $c_{2}$. Second, we may note that the factors that affect $r^{n}$ differ from the factors affecting $r^{*}$. For instance, a change in the functional distribution of income affect $r^{*}$ through a demand-side channel but, as (32) highlights, it affects $r^{n}$ through a supply-side channel (i.e., by altering $\bar{u}$ ). This is because demand shocks affect output growth in the short run and, in turn, the latter affects the saving rate so that the initial impact of the demand shock on $r^{n}$ - but not the corresponding supply shock that occurs through the induced change in $\bar{u}-$ is fully offset by the subsequent variation in the saving rate. Since output growth is equal to the "natural" growth rate in steady growth, the supply-side effect disappears in the long run thus letting the demand shock reappear. 


\section{4.- Transient dynamics}

The next question we address is the stability of the adjustment process to the new equilibrium after being shocked away in an economy described by the model postulated above. We want to make sure, as Joan Robinson would put it, that the fullyadjusted positions can be reached in historical time. If so, this will imply a successful "traverse" from one path to another (Hicks, 1965, p. 184). To simplify the discussion, we will sidestep the problem that the adjustment process may be short-circuited if the zero lower bound constraint binds at any time and will focus instead on the possibility that the new equilibrium may be unstable even when the zero lower bound constraint does not bind. First, we analyze the stability of the long-run equilibrium when the economy does exhibit neither hysteresis effects nor AID and, then, we discuss whether and how the previous results are affected when the economy does exhibit these two features.

\section{1.- Transient dynamics without hysteresis and AID}

In this section we show that an economy described by the model expounded above and that is not subject to the zero lower bound constraint at any time during the adjustment process successfully reaches a new steady growth position provided certain conditions are met. This issue is rather technical so we tackle it in detail in appendix A where we analyse formally the (local) stability of a non-linear dynamic system extracted from the model presented above when the $\mathrm{CB}$ sets real interest rates according to the following Taylor-type policy rule: ${ }^{18}$

$$
r=r^{*}(m)+\alpha\left(\pi-\pi^{*}\right)
$$

where $\alpha$ is the response coefficient of monetary policy to changes in the inflation gap, i.e., the difference between the actual and the target inflation rate. We show below that, for a wide range of parameter values, equilibrium $P^{*}=\left(\pi^{*}, u^{*}(m), u^{*}(m)\right)$ is (locally) stable if the following three conditions are satisfied:

and

$$
\begin{aligned}
& \Delta_{1}=\frac{f_{u} u^{*}(m)-\frac{\psi}{v_{u}{ }^{*}(m)}}{c_{\hat{y}}}-g_{n}-v f_{u} u^{*^{2}}(m) \prec 0 \\
& c_{\pi}+\alpha_{C_{r}} \succ 0 \\
& {\left[\frac{-f_{u} u^{*^{2}}(m)+u^{*}(m) c_{\hat{y}} v+(\psi / v)-c_{\hat{y}} f_{u} v_{u} *^{3}}{c_{\hat{y}}}\right] \succ 0}
\end{aligned}
$$

Conditions (34) and (36) are satisfied for the set of parameter values chosen for the simulation exercise (see table 1 below) so the economy will be (locally) stable if:

$$
\alpha \succ \alpha^{*}=\frac{-c_{\pi}}{c_{r}}
$$

This means that, if $c_{\pi} \succ 0$, then response coefficient $\alpha$ does not need to satisfy Taylor's principle (Taylor, 1993) (i.e., that $\alpha \succ 0$ ) to render the economy locally stable. By contrast, if $c_{\pi} \prec 0$, satisfying Taylor's principle does not guarantee the stability of the system. Since $b_{\pi} \prec 0$ by assumption, the sign of $c_{\pi}=s_{\pi}-b_{\pi}$ depends on the sign and size of $s_{\pi}$ as well as on the size of $b_{\pi}$. Therefore, if the CB is to provide a nominal anchor to the economy, then it will have to be more responsive to changes in the actual inflation rate if the Keynesian "debt" effect dominates $\left(c_{\pi} \prec 0\right)$ than if the Neoclassical "inflation tax" effect prevails $\left(c_{\pi} \succ 0\right)$. In other words, whether the economy exhibits a Keynesian or a Neoclassical regime affects $\alpha^{*}$ but does not have further repercussions 
on economic stability as long as $\alpha \succ \alpha^{*}$ and the zero lower bound does not bind. Moreover, we have that:

$$
\begin{gathered}
\frac{\partial \Delta_{1}}{\partial u^{*}(m)}=f_{u}\left(\frac{1}{c_{\hat{y}}}-2 v u^{*}(m)+\frac{\psi}{v_{C_{\hat{y}}} u^{*^{2}(m)}}\right) \frac{\prec}{\succ} 0 \\
\frac{\partial \Delta_{1}}{\partial C_{\hat{y}}}=\frac{1}{c_{\hat{y}}^{2}} \cdot u^{*}(m) \cdot\left(\frac{\psi}{v \cdot u^{*}(m)^{2}}-f_{u}\right) \frac{\prec}{\succ} 0
\end{gathered}
$$

Expression (37) tells us that a change in the desired degree of capacity utilization $u^{*}$ brought about, for instance, by a change in $m$ may, in principle, make $P^{*}$ locally unstable - if it makes $\Delta_{1}$ become positive - albeit our own calculations based on the parameter values shown in table 1 suggest that the change would have to be extremely large for this to be the case. We may also note that partial derivative $s_{m}$ does not show up in the stability conditions above. Thus, changes in $m$ and, hence, in the functional distribution of income, cannot undermine the stability of $P^{*}$. In turn, this means that whether the economy exhibits a "wage-led" or a "profit-led" regime is irrelevant for macroeconomic stability provided the zero lower bound constraint does not bind. However, the distribution regime the economy exhibits remains an important datum since, as noted above, it affects $r^{*}$ and, hence, the likelihood that an aggregate demand deficiency occurs. Finally, expression (38) is rather similar to expressions (31) and (32). It tells us that, for example, an increase in the stabilizing power of fiscal automatic stabilizers $b_{\hat{y}}$ and, hence, in $c_{\hat{y}}$, apparently has an ambiguous effect on the sign of $\Delta_{1}$. Notwithstanding it, if we look at (34), we see that an increase in $C_{\hat{y}}$ actually renders $\Delta_{1} \succ 0$ less likely hence reinforcing stability. Thus, as conventional wisdom has it, the more powerful automatic stabilizers are the more stable the economy becomes.

\section{2.- Transient dynamics with hysteresis and AID}

We now address the consequences for macroeconomic stability of the presence of hysteresis effects and AID. To do so, we need to derive three additional equations for simulation purposes. First, the presence of hysteresis effects means that the CIER is now determined by the time path of the employment rate and that, in turn, changes in the CIER affect the CICU as depicted in expression (9). If the take logarithms in (9) and differentiate it with respect to time we get:

$$
\frac{\dot{\bar{u}}(m)}{\bar{u}(m)}=\frac{\dot{\bar{e}}(m)}{\bar{e}(m)}+g_{n}-g
$$

Next, in order to capture the presence of a zero lower bound constraint on nominal interest rates we need to rewrite the expression that depicts the behaviour of the real interest rate. As before, we assume that the CB knows $r^{*}$ and that it sets (real) interest rates according to policy rule (33) so that:

$$
r_{t}=\left\{\begin{array}{ccc}
\omega_{t}=\mu-\pi_{\mathrm{t}} & \text { if } & r^{*}+\alpha \cdot\left(\pi_{t}-\pi^{*}\right) \prec \omega_{t} \\
r^{*}+\alpha \cdot\left(\pi_{t}-\pi^{*}\right) & \text { if } & r^{*}+\alpha \cdot\left(\pi_{t}-\pi^{*}\right) \geq \omega_{t}
\end{array}\right.
$$

Therefore, the (long-term) actual real interest rate is determined by a Taylor-type monetary policy rule when the zero bound constraint does not bind or else is equal to the difference between the term/risk premium on long-term rates and the inflation rate. Finally, differentiation of (5) yields equation (42) in appendix A which describes the dynamics of capacity utilization. Hence, the model we will use for simulation purposes 
is made up of the following equations: (10), (11), (14), (16), (23), (28), (29), (39), (40) and (42). Simulation results are shown in figures 1 through 22 in appendix B. Table 1 contains the parameter values, the initial conditions and the values of the operators describing the stability conditions. Parameter values are justified in appendix B. Tables 2 and 3 summarize the different shocks and scenarios considered in each simulation exercise. The second column in tables 2 and 3 explain the type of shock analysed in each exercise whereas the third column identifies those parameter values of each exercise that differ from the values reported in table 1.

\subsection{1.- The impact on macroeconomic volatility}

Figures 1 through 3 show the behaviour of the inflation rate, capacity utilization and the employment rate in the aftermath of an adverse shock to the inflation rate when the economy exhibits neither hysteresis effects nor AID. For the set of parameter values reported in table 1 the economy exhibits self-sustained oscillations. The former are the result of the interplay in a non-linear context of an (unstable) multiplier-accelerator mechanism and the stabilizing behaviour of real interest rates. Figures 4 through 6 show the time-path of the same variables when the economy exhibits hysteresis effects. The presence of hysteresis dampens oscillations. This is because, when the employment rate decreases, the CIER decreases along with it and this, in turn, cushions the downward pressure on the inflation rate. Conventional wisdom suggests that this "cushion" effect should weaken rather than reinforce macroeconomic stability because, as inflation decreases, the $\mathrm{CB}$ will lower interest rates and this will spur aggregate spending thereby helping to reverse the initial shock. However, the simulation exercise shows that, at least in the context of our model, the presence of hysteresis ameliorates macroeconomic volatility. The simulation exercise also revealed that the higher parameter $\zeta$ is the more dampened oscillations become. Further, figures 7 through 9 suggest that the presence of AID also tends to dampen oscillations. In short, the presence of hysteresis and AID appears to reinforce the stabilizing power of monetary policy.

\subsection{2.- The impact of shocks to the inflation rate}

As is well-known, the existence of (unit-root) hysteresis implies that persistent but nevertheless transitory shocks may have permanent effects on the economy. For instance, figure 6 shows that a disinflation process in the wake of an adverse shock that raised the inflation rate above its target $\left(\pi_{0}=0.035 \succ \pi^{*}\right)$ imposes on the economy a permanently lower employment rate. However, as pointed out, systems exhibiting (unitroot) hysteresis also possess the "reversibility" property. Following with the previous example, this means that if the economy is subject to a shock of the same intensity but opposite sign (e.g. $\pi_{0}=0.005 \prec \pi^{*}$ ), the employment rate now stabilizes at a higher level (see figure 16). Importantly, the long-run decrease in the employment rate brought about by the unfavourable shock is equal to the long-run increase brought about by the favourable supply shock.

Next, we address the consequences for unemployment of inflation shocks when the economy exhibits hysteresis effects and AID. ${ }^{19}$ In figure 14, the disinflation process brought about by an adverse inflation shock makes the employment rate settle at 0.884 in the long run, well below its initial level at 0.9. By contrast, in the wake of a shock of equal intensity but opposite sign the employment rate stabilizes at 0.908 (see figure 15) so the "reversibility" property typically exhibited by zero/unit root systems is violated. The existence of a negative bias to the employment rate is confirmed in the stochastic simulation exercise depicted in figures 17 through 19. Figure 17 shows the time path of 
the employment rate when the economy is subject to a sequence of random inflation shocks $\varepsilon_{\pi}$. The latter were generated by a normal probability distribution of zero mean and standard deviation equal to 0.0096 (see figure 19). In the absence of AID, the employment rate rapidly drops off and converges to zero. Figure 18 shows the replication of the exercise when the economy exhibits hysteresis effects and AID. The employment rate now fluctuates around a decreasing trend. Therefore, as far as inflation are concerned, the presence of hysteresis effects and AID reinforces macroeconomic stability, blocks off the "reversibility" property and, crucially, it imparts a long-term negative bias on the employment rate in the sense that, if the economy is initially at equilibrium and is subjected to a unfavourable supply shock that raises the inflation rate and this is subsequently followed by a second shock of the same intensity but in the opposite direction then the employment rate does not return to the initial equilibrium but stabilizes at a lower level.

\subsection{3.- The impact of demand shocks}

We now investigate the long-run effect on the employment rate of demand shocks when the CIER exhibits hysteresis effects. This affects to shocks associated to changes in the functional distribution of income as well as to shocks associated to changes in the private saving rate and fiscal policy. The presence of an inflationtargeting $\mathrm{CB}$ implies that the short-run impact of a demand shock will be, at least partially, offset by changes in real interest rates. This is because the demand shock affects $r^{*}$ and, if the CB periodically updates its estimate of $r^{*}$, the impact on AD is offset by a change in the real interest rate. ${ }^{20}$ For instance, if the $\mathrm{CB}$ sets interest rates according to a Taylor-type policy rule like (35) then, a rise (fall) in $m$ when the economy is "profit-led" ("wage-led") (i.e., a favourable demand shock) prompts an upward revision of $r^{*}$ and, hence, an increase in the actual real interest rate. Figures 10 and 11 depict the long-run impact on the employment rate of an increase and a decrease in $m$ respectively when the economy is "profit-led". In the former case, the increase in $m$ leads to a decrease in $u^{*}$ that stimulates investment spending and, hence, to an increase in $r^{*}$ whereas, in the latter case, the opposite holds. ${ }^{21}$ The simulation exercise confirmed that, in the absence of AID, shocks do not affect the employment rate in the long run. In particular, demand shocks determine the time path of the employment rate but do not affect the level at which it settles in the long run which is equal to the initial (supply-determined) one.

Next, we analyse how the previous results vary when there is both hysteresis effects and AID. Figure 12 shows the case of a favourable demand shock whereas figure 13 shows the case of an unfavourable one. In both cases, the employment rate settles below its initial level at 0.9 , albeit the long-term decrease is clearly more marked when the shock is unfavourable. Therefore, the presence of AID makes demand shocks have an adverse long-term impact on the employment rate even when they are expansionary. This is confirmed in the stochastic simulation exercise depicted in figures 20 through 22. As with inflation shocks, we subject the aggregate saving rate to random shocks $\varepsilon_{s}$ drawn from a normal probability distribution of zero mean and standard deviation equal to 0.0084 (see figure 22). Figure 20 shows the time path of the employment rate when the economy (only) exhibits hysteresis effects whereas figure 21 shows its time path when the economy exhibits hysteresis effects and AID. In the former case, the employment rate hovers in the short run around a stationary trend whereas, in the latter case, the employment rate exhibits a declining trend. In short, demand shocks are neutralized by changes in real interest rates induced by the $\mathrm{CB}$ so they do affect the 
employment rate in the short run but do not affect it in the long run unless the economy exhibits AID; in this latter case they affect it adversely even when shocks are expansionary.

To finish off this section let us recall that a change in $m$ gives rise to a short-run change in the actual inflation rate, a permanent demand shock (of ambiguous sign), and an initial supply shock represented by a change in the CIER. The upshot of the previous discussion was that, if the economy exhibits hysteresis effects and AID, the interaction of short-run changes in the inflation rate and demand shocks will lead to a lower employment rate in the long run. To these effects, we need to add the initial favourable (unfavourable) supply shock when $m$ decreases (increases) which will bring about an increase (decrease) in the CIER. If $m$ increases, the (initial) reduction in the CIER will exacerbate the long-run negative bias imparted on the employment rate by the two previous effects. By contrast, if $m$ decreases, the net long-run effect on the employment rate becomes uncertain and depends on the relative strength of the three separate effects.

\section{5.- Summary and conclusion}

In this study we analysed the long-run impact on the employment rate of a change in the degree of monopoly power as measured by the average mark up in an economy characterized by the existence of (i) a short-run "inflation barrier" referred to as the "constant inflation employment rate" (CIER) that may exhibit hysteresis effects, (ii) a central bank (CB) that sets interest rates in order to hit an inflation target and (iii) the presence of "asymmetric inflation dynamics" (AID) put down to the existence of downward money wage rigidity. For that purpose, we postulated a macroeconomic model for a closed economy with a government sector that incorporates the abovementioned features. We identified three different effects of a change in the average mark up: (i) a permanent change in the level of aggregate demand stemming from a change in the functional distribution of income, (ii) an initial change in the CIER and (iii) a short-run variation in the inflation rate.

We obtained several results. First, we found that, in an economy characterized by the above features except AID, a change in the mark up only affects the employment rate in the long run insofar as the former initially affects the CIER and the inflation rate. In particular, an increase in the average mark up leads to a decrease in the employment rate and vice-versa. We argued that this occurs because the permanent demand shock brought about by the change in the functional distribution of income leads to a change in the steady growth neutral interest rate and this, in turn, is passed through into the actual real interest rate by virtue of the monetary policy rule of the $\mathrm{CB}$. Thus, in this scenario a change in the mark up only leads to a long-run increase in the employment rate when it contracts.

Second, we showed that, when the economy also exhibits AID, a change in the average mark up is less effective and may even be counterproductive. This is because the long-run impact on the employment rate of the demand shock, even when it is expansionary, is adverse. Therefore, in this second scenario, an increase in the average mark up, even when coupled by an expansionary demand shock, always leads to a longrun decrease in the employment rate. Further, a decrease in the mark up only brings about a long-run increase in the employment rate if the net adverse effect of the permanent demand shock (even it is expansionary) is more than offset by the sum of the favourable effects stemming from the initial reduction in the inflation rate and the rise in the CIER. More generally, we showed by means of a sequence of simulation exercises that the joint presence of hysteresis and AID in the type of economy sketched above (i) attenuates macroeconomic volatility and (ii) blocks off the "reversibility" property 
exhibited by zero/unit root systems in the wake of inflation shocks. Third, we found that, whether the economy exhibits a "wage-led" or a "profit-led" macroeconomic regime is irrelevant for macroeconomic performance as long as the economy does not exhibit an aggregate demand deficiency problem.

Fourth, we argued that, despite the importance of the above results, this does not mean that changes in the functional distribution of income may not affect macroeconomic performance favourably. In this respect, we showed that the functional distribution of income affects the neutral interest rate in the short run and in the long run and, thus, it affects the probability that the economy exhibits an aggregate demand deficiency. We then argued that, although proponents of the NC approach may eventually accept that the functional distribution of income is one potential factor affecting aggregate demand and, hence, the neutral interest rate, they nevertheless reject the notion that it affects the steady growth neutral interest rate since they assume that the latter is mainly determined by the (positive) rate of time preference of the representative household and the "natural" growth rate. As a result of it, they fail to perceive the potentially beneficial impact of the functional distribution of income on macroeconomic performance. We then argued that liquidity preference theory precludes the existence of a positive lower threshold to the steady growth neutral interest rate and this, in turn, implies that factors like the fiscal policy stance, the functional distribution of income, and the degree of liquidity preference are determinants of macroeconomic performance.

Lastly, we distinguished between a Keynesian regime and a Neoclassical regime according to whether an increase in the inflation rate leads to an increase (Keynesian) or to a decrease (Neoclassical) in the neutral interest rate and showed that the regime the economy exhibits determines the condition that the monetary policy rule of the $\mathrm{CB}$ must satisfy to provide a nominal anchor to the economy. A corollary of our analysis was that Taylor's principle may not hold when changes in the inflation rate affect aggregate demand directly.

\section{Appendix A}

This appendix deals with the computation of the equilibrium points and stability conditions of the dynamical system that results from the economic model postulated in section 3. For the sake of the argument, we make a number of simplifying assumptions. First, we assume that the CB knows $r^{*}$. Second, we impose the conditions $\phi_{U}=\phi_{L}$ and $\bar{f}=\left(g_{n} / v \cdot u^{*}(m)\right)$. The former means that we assume the economy does not exhibit AID whereas the latter means that firms' output growth expectations are firmly anchored to its secular growth rate so we remove any instability that may result from changes in firms' profit expectations. Admittedly, this provides the economy with a built-in stabilizing mechanism but it certainly makes the system much easier to handle. Third, we assume that $r^{*}$ is positive and high enough so as to make the zero lower bound not bind. Finally, the analysis focuses on the local stability of the economy. Taking these limitations into account, we have that:

$$
\frac{\dot{u}}{u}=\hat{y}-g
$$

and substituting (16), (28), (29) and (33) into (42) yields:

$$
\dot{u}=h(u, \pi)
$$

Next, if we assume that $\zeta=0$ (i.e., the CIER does not exhibit hysteresis), we can rewrite (39) as: 


$$
\dot{\bar{u}}=\bar{u} \cdot\left(g_{n}-g\right)
$$

and substituting (28) into (16) and then into (44) yields:

$$
\dot{\bar{u}}=\bar{u} \cdot\left[g_{n}-v \cdot u \cdot\left(\bar{f}+f_{u} \cdot\left(u-u^{*}(m)\right)\right]\right.
$$

Therefore, our dynamical system is made up of equations (10) - with $\phi_{U}=\phi_{L}$ -, (43) and (45), so we may obtain the singular points by setting $\dot{\pi}=\dot{u}=\dot{\bar{u}}=0$ which yields two singular points:

$$
\begin{aligned}
& u_{1,2}^{*}=\frac{\bar{f} v-v f_{u} u^{*}(m) \pm \sqrt{\left(-\bar{f} v+v f_{u} u^{*}(m)\right)^{2}+4 v f_{u} g_{n}}}{-2 v f_{u}} \\
& \pi_{1,2}^{*}=\frac{\bar{f}-c_{1}+f_{u}\left(u-u^{*}(m)\right)-c_{r} r^{*}+c_{r} \alpha \pi^{*}+\frac{\psi}{v_{u}{ }^{*}(m)}-c_{\hat{y}} v \bar{f} u^{*}(m)-c_{\hat{y}} v f_{u} u^{*^{2}(m)+c_{\hat{y}} v f_{u} u^{*^{2}}(m)}}{c_{\pi}+c_{r} \alpha}
\end{aligned}
$$

where the only one with economic meaning is:

$$
P^{*}=\left(\pi^{*}, u^{*}(m), u^{*}(m)\right)
$$

Next, a necessary and sufficient condition for local stability is: ${ }^{22}$

$$
\begin{gathered}
\Delta_{1}=\lambda_{1}+\lambda_{2}+\lambda_{3}=2 \delta+\lambda_{3} \prec 0 \\
\Delta_{2}=\lambda_{1} \cdot \lambda_{2} \cdot \lambda_{3}=\left(\delta^{2}+\beta^{2}\right) \cdot \lambda_{3} \prec 0 \\
\Delta_{3}=\lambda_{1} \lambda_{2}+\lambda_{1} \lambda_{3}+\lambda_{2} \lambda_{3}=\delta^{2}+\beta^{2}+2 \delta \lambda_{3} \succ 0
\end{gathered}
$$

and by Orlando's formula (see Gantmacher, 1954, p. 197):

$$
\Delta_{4}=-\left(\lambda_{1}+\lambda_{2}\right)\left(\lambda_{1}+\lambda_{3}\right)\left(\lambda_{2}+\lambda_{3}\right)=-2 \delta\left(\delta^{2}+\beta^{2}+2 \delta \lambda_{3}+\lambda_{3}^{2}\right) \succ 0
$$

where the $\lambda^{\prime}$ s are the eigenvalues of the (linearized) dynamical system, $\delta$ is the real part of the complex conjugate eigenvalues, $\Delta_{1}=\operatorname{Tr}(J), \Delta_{2}=\operatorname{Det}(J), \Delta_{3}=J_{11}+J_{22}+J_{33}$, $\Delta_{4}=-\Delta_{1} \Delta_{3}+\Delta_{2}$ and $J$ is the Jacobian matrix of the linearized system. In turn, the $J_{i i}$ are the principal minors (of order 2 ) of $J$, i.e., the determinants of the matrices that are obtained after deleting the i-th row and the i-th column. Thus, a necessary and sufficient condition for the non-linear system made up of equations (10), (43) and (45) to be locally asymptotically stable is:

$$
\begin{gathered}
\Delta_{1}=\frac{f_{u} u^{*}(m)-\frac{\psi}{v u^{*}(m)}}{c_{\hat{y}}}-g_{n}-v f_{u} u^{*^{2}}(m) \prec 0 \\
\Delta_{2}=\frac{\left(c_{\pi}+\alpha c_{r}\right) \cdot u^{*}(m) \phi}{c_{\hat{y}}} \cdot\left(-g_{n}-v f_{u} u^{*^{2}}(m)\right) \prec 0 \\
\Delta_{3}=\frac{\left(c_{\pi}+\alpha c_{r}\right) \phi u^{*}(m)}{c_{\hat{y}}} \succ 0
\end{gathered}
$$

and

$$
\Delta_{4}=\frac{\left(c_{\pi}+c_{r} \alpha\right) \phi}{c_{\hat{y}}}\left[\frac{-f_{u} u^{*^{2}}(m)+u^{*}(m) c_{\hat{y}} v+(\psi / v)-c_{\hat{y}} f_{u} v_{u} *^{3}}{c_{\hat{y}}}\right] \succ 0
$$

As a result of it, the stability of the system requires that conditions $c_{\pi}+\alpha c_{r} \succ 0$, $\Delta_{1} \prec 0$ and $\Delta_{4} \succ 0$ be satisfied. Furthermore, there exists a value $\alpha{ }^{*}$ of the response coefficient of the monetary policy rule of the CB for which the local stability of the system changes dramatically. We may obtain $\alpha^{*}$ by setting $\Delta_{4}=0$. 


$$
\alpha^{*}=\frac{-c_{\pi}}{c_{r}} \frac{\succeq}{\prec} 0
$$

so the system will be unstable if $\alpha \prec \alpha^{*}$ and vice-versa.

\section{Appendix B}

The simulation exercise was aimed at exploring the implications of the existence of hysteresis and AID. Table 1 reports the values of the parameters of the model, including $r^{*}$ and $\bar{f}$, and the initial conditions whereas tables 2 and 3 report the values of those parameters and initial conditions whose values may differ in successive simulation exercises from those reported in table 1. The parameters and initial conditions responsible for the single shock are underlined. For the sake of convenience, we assume that $s_{m}=\bar{u}_{m}=0$. The values of the parameters were chosen according to the values typically reported in the literature. For instance, the inflation target for many CBs is 2 per cent. The literature usually reports that the technical output-capital ratio $v$ is about 0.3. Studies for the U.S. economy suggest that the CICU is about 82 percent (see Garner, 1994 and Corrado and Mattey, 1997) and the value assigned to $\phi_{U}$ stems from results in McElhattan (1985) who finds that, for each percentage point that capacity utilization exceeds 82 percent, inflation accelerates by about 0.15 percentage points. As for $\pi^{C R}$, we follow Akerlof et al. (1996) and assume that the presence of DMWR starts to bite when the actual inflation rate is less than 3 percent. This implies that, if $\phi_{\pi}=4$ and $\phi_{U}=0.15$, the inflation rate ceases to decrease when it is equal to -0.0075 which is roughly the level at which the Japanese inflation rate settled after 1998. Next, the resulting value for the short-term real interest rate - taking into account that $r^{*}$ is a long-term interest rate and so we need to subtract the term premium to obtain the former — is roughly the value of the real federal funds rate over the 1960-1998 period in the U.S.: 2.55 percent (Reifschneider and Williams, 2000, p. 950). As for the parameters in the saving and investment function, we set them so as to render the economy stable and, as mentioned above, we set $\bar{f}$ equal to its steady growth value to make the model easier to handle. The standard deviation of the normal distributions used to generate a set of random inflation and demand shocks were taken from Orphanides and Wieland (2000, p. 1373) who estimate a three-equations NC-type model for the Euro area for the period 1976-1998 and report a standard deviation of inflation and demand shocks equal to 0.96 and 0.84 respectively. Finally, the subscripts of the variables in table 1 denote the values that the parameters adopt in different simulation exercises.

\begin{tabular}{|c|c|c|c|c|}
\hline$f_{u, 0}=0.015$ & $c_{r}=2.5$ & $\zeta_{2}=0.3$ & $u^{*}=u_{0}=\bar{u}_{0}=0.8$ & $g_{n}=0.03$ \\
\hline$f_{u, 1}=0.3$ & $c_{\pi}=-0.1$ & $s_{m}=\bar{u}_{m}=0$ & $\alpha^{*}=0.04 \alpha=0.5$ & $\partial r^{*} / \partial g_{n}=1.0 \hat{6}$ \\
\hline$\pi^{*}=0.02$ & $\pi_{0}^{C R}=\phi_{\pi, 0}=0$ & $\pi_{1}^{C R}=0.03$ & $e_{0}=\bar{e}_{0}=0.9$ & $\Delta_{1}=-0.12210$ \\
\hline$c_{1}=0.14$ & $\phi_{U}=0.15$ & $\phi_{\pi, 1}=4$ & $v=0.3$ & $\Delta_{2}=-0.00302$ \\
\hline$c_{2}=-0.03$ & $\zeta_{0}=0$ & $\bar{f}=0.125$ & $\psi=0.035$ & $\Delta_{3}=0.092$ \\
\hline$c_{\hat{y}}=1.5$ & $\zeta_{1}=0.1$ & $\mu=0.01$ & $r^{*}=0.035$ & $\Delta_{4}=0.029957$ \\
\hline
\end{tabular}

Table 1: Parameter values, initial conditions and operators 


\begin{tabular}{|c|c|c|}
\hline Fig. & Single shock & $\begin{array}{c}\text { Parameter values (when they differ from those } \\
\text { reported in table 1) }\end{array}$ \\
\hline Fig. 1 & $\begin{array}{c}\text { Unfavourable inflation } \\
\text { shock }\end{array}$ & Absence of hysteresis and AID: $\pi_{0}=0.035$ \\
\hline Fig. 2 & $\begin{array}{l}\text { Unfavourable inflation } \\
\text { shock }\end{array}$ & Absence of hysteresis and AID: $\pi_{0}=0.035$ \\
\hline Fig. 3 & $\begin{array}{l}\text { Unfavourable inflation } \\
\text { shock }\end{array}$ & Absence of hysteresis and AID: $\pi_{0}=0.035$ \\
\hline Fig. 4 & $\begin{array}{l}\text { Unfavourable inflation } \\
\text { shock }\end{array}$ & 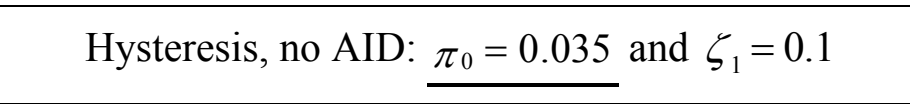 \\
\hline Fig. 5 & $\begin{array}{l}\text { Unfavourable inflation } \\
\text { shock }\end{array}$ & Hysteresis, no AID: $\pi_{0}=0.035$ and $\zeta_{1}=0.1$ \\
\hline Fig. 6 & $\begin{array}{c}\text { Unfavourable inflation } \\
\text { shock }\end{array}$ & Hysteresis, no AID: $\pi_{0}=0.035$ and $\zeta_{1}=0.1$ \\
\hline Fig. 7 & $\begin{array}{l}\text { Unfavourable inflation } \\
\text { shock }\end{array}$ & AID, no hysteresis: $\frac{\pi_{0}=0.035}{\phi_{\pi, 1}=4}, \pi_{1}^{C R}=0.03$ and \\
\hline Fig. 8 & $\begin{array}{l}\text { Unfavourable inflation } \\
\text { shock }\end{array}$ & AID, no hysteresis: $\frac{\pi_{0}=0.035}{\phi_{\pi, 1}=4} \pi_{1}^{C R}=0.03$ and \\
\hline Fig. 9 & $\begin{array}{l}\text { Unfavourable inflation } \\
\text { shock }\end{array}$ & AID, no hysteresis: $\frac{\pi_{0}=0.035}{\phi_{\pi, 1}=4} \pi_{1}^{C R}=0.03$ and \\
\hline Fig. 10 & $\begin{array}{l}\text { Expansionary demand } \\
\text { shock }\end{array}$ & $\begin{array}{c}\text { Hysteresis, no AID: } u^{*}=0.75, f_{u, 1}=0.3, \\
\pi_{0}=0.02 \text { and } \zeta_{2}=0.3\end{array}$ \\
\hline Fig. 11 & $\begin{array}{l}\text { Contractionary } \\
\text { demand shock }\end{array}$ & $\begin{array}{l}\text { Hysteresis, no AID: } u^{*}=0.85, f_{u, 1}=0.3, \\
\pi_{0}=0.02 \text { and } \zeta_{2}=0.3\end{array}$ \\
\hline Fig. 12 & $\begin{array}{l}\text { Expansionary demand } \\
\text { shock }\end{array}$ & $\begin{array}{c}\text { Hysteresis and AID: } u^{*}=0.75, f_{u, 1}=0.3, \pi_{0}=0.02, \\
\pi_{1}^{C R}=0.03, \phi_{\pi, 1}=4 \text { and } \zeta_{2}=0.3\end{array}$ \\
\hline Fig. 13 & $\begin{array}{l}\text { Contractionary } \\
\text { demand shock }\end{array}$ & $\begin{array}{c}\text { Hysteresis and AID: } u^{*}=0.85, f_{u, 1}=0.3, \pi_{0}=0.02, \\
\pi_{1}^{C R}=0.03, \phi_{\pi, 1}=4 \text { and } \zeta_{2}=0.3\end{array}$ \\
\hline Fig. 14 & $\begin{array}{l}\text { Unfavourable inflation } \\
\text { shock }\end{array}$ & $\begin{array}{l}\text { Hysteresis and AID: } \frac{\pi_{0}=0.035,}{\text { and } \zeta_{1}=0.1} \pi_{1}^{C R}=0.03, \phi_{\pi, 1}=4 \\
\text {. }\end{array}$ \\
\hline Fig. 15 & $\begin{array}{l}\text { Favourable inflation } \\
\text { shock }\end{array}$ & $\begin{array}{c}\text { Hysteresis and AID: } \frac{\pi_{0}=0.005}{\text { and } \zeta_{1}=0.1}, \pi_{1}^{C R}=0.03, \phi_{\pi, 1}=4 \\
\text { a }\end{array}$ \\
\hline Fig. 16 & $\begin{array}{c}\begin{array}{c}\text { Favourable inflation } \\
\text { shock }\end{array} \\
\end{array}$ & Hysteresis, no AID: $\underline{\pi_{0}=0.005}$ and $\zeta_{1}=0.1$ \\
\hline
\end{tabular}

Note: The parameters underlined in the third column are the ones that trigger the shock

Table 2: Summary of parameter values and initial conditions in the simulation exercises with a single shock 


\begin{tabular}{|l|c|c|}
\hline \multicolumn{1}{|c|}{ Fig. } & Shocks & $\begin{array}{c}\text { Parameter values (when they differ from those } \\
\text { reported in table 1) }\end{array}$ \\
\hline Fig. 17 & $\begin{array}{c}\text { Stochastic inflation } \\
\text { shocks }\end{array}$ & Hysteresis, no AID: $\pi_{0}=0.02$ and $\zeta_{2}=0.3$ \\
\hline Fig. 18 & $\begin{array}{c}\text { Stochastic inflation } \\
\text { shocks }\end{array}$ & $\begin{array}{c}\text { Hysteresis and AID: } \pi_{0}=0.02, \pi_{1}^{C R}=0.03, \phi_{\pi, 1}=4 \\
\text { and } \zeta_{1}=0.1\end{array}$ \\
\hline Fig. 19 & $\begin{array}{c}\text { Stochastic inflation } \\
\text { shocks }\end{array}$ & Drawn from a normal distribution \\
\hline Fig. 20 & $\begin{array}{c}\text { Stochastic demand } \\
\text { shocks }\end{array}$ & Hysteresis, no AID: $\pi_{0}=0.02$ and $\zeta_{1}=0.1$ \\
\hline Fig. 21 & $\begin{array}{c}\text { Stochastic demand } \\
\text { shocks }\end{array}$ & Hysteresis and AID: $\pi_{0}=0.02, \pi_{1}^{C R}=0.03, \phi_{\pi, 1}=4$ \\
and $\zeta_{1}=0.1$
\end{tabular}

Table 3: Summary of parameter values and initial conditions in the simulation exercises with a stochastic sequence of shocks

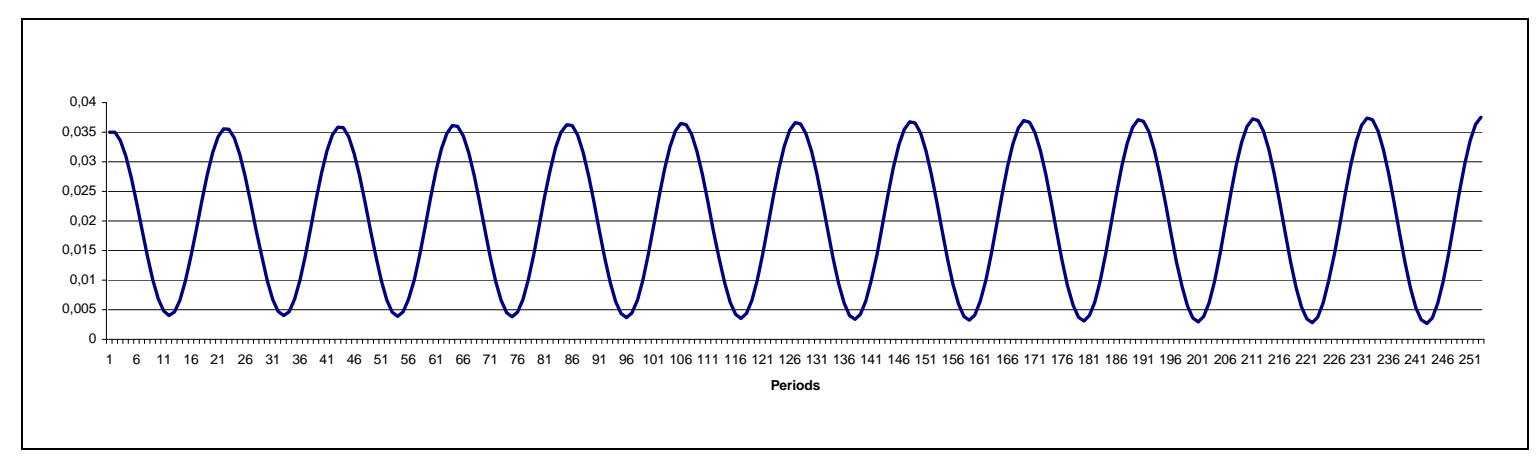

Fig.1: Inflation rate

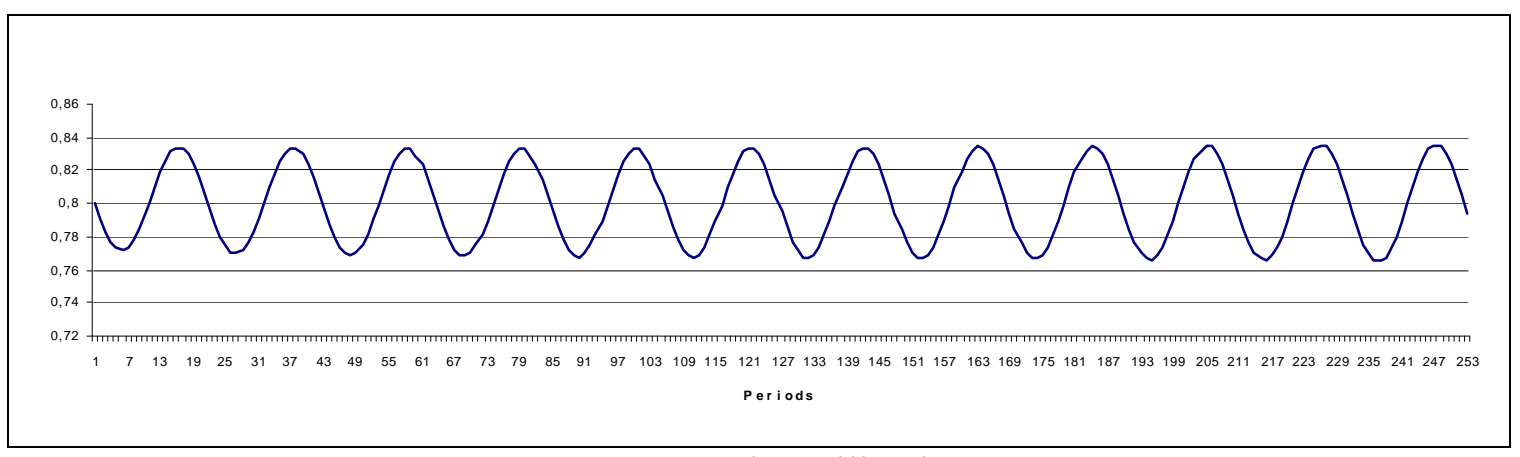

Fig. 2: Capacity utilization 


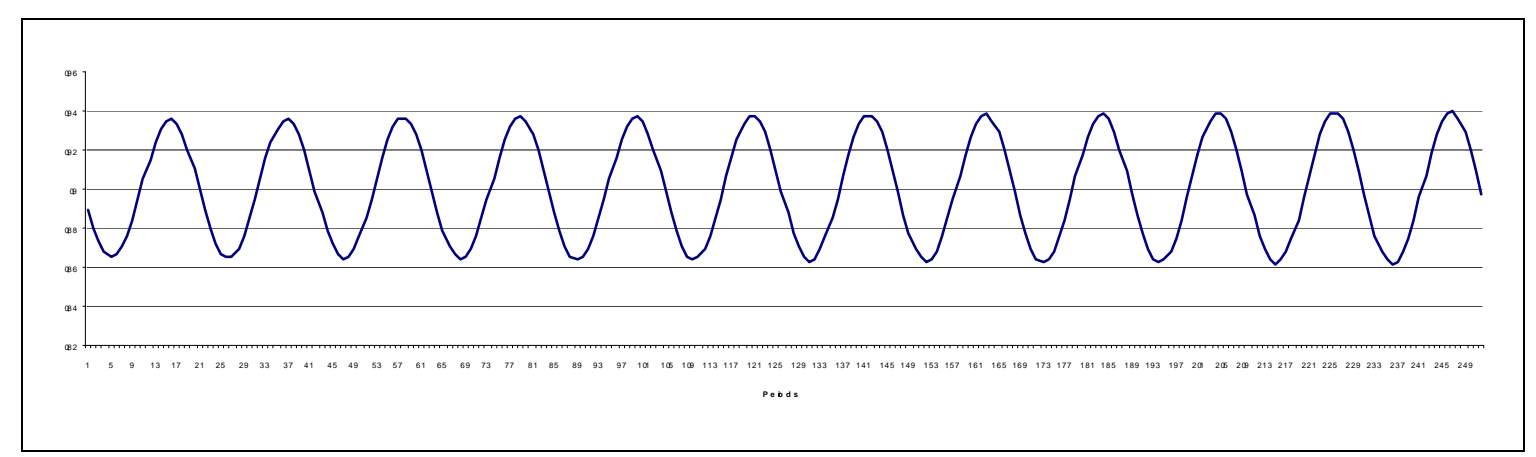

Fig. 3: Employment rate

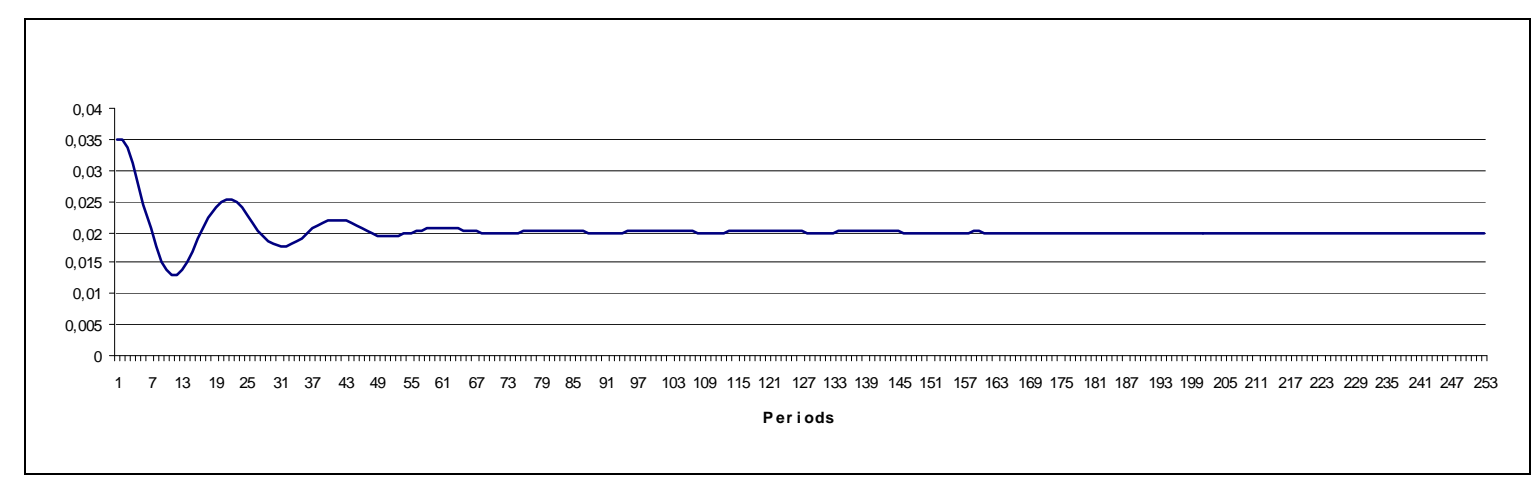

Fig. 4: Inflation rate

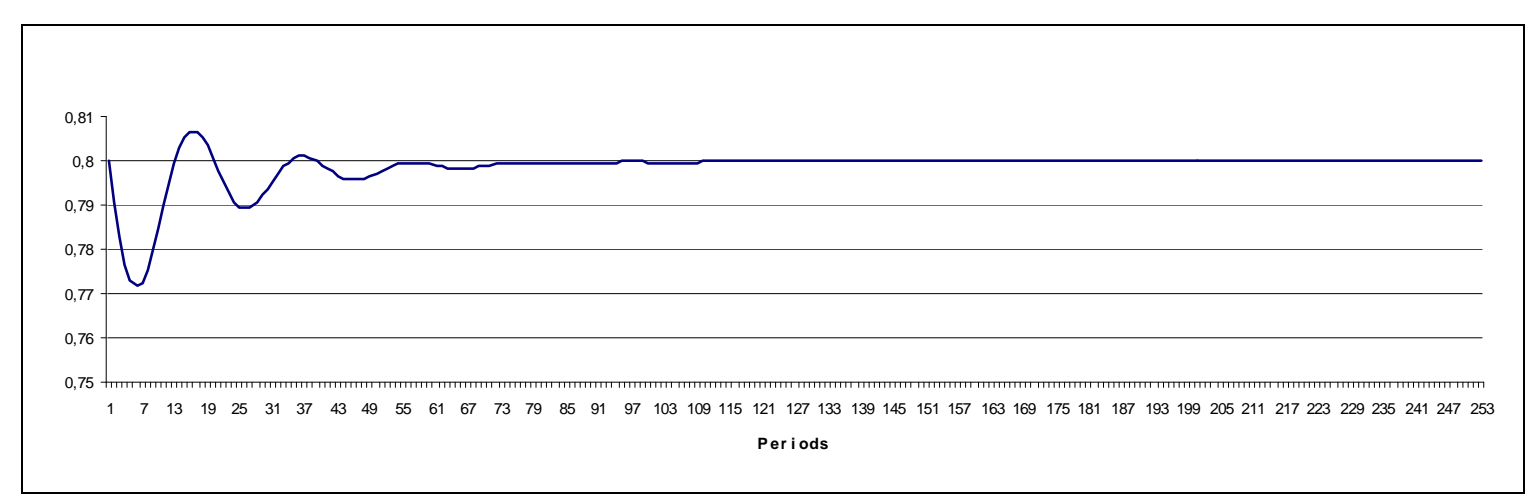

Fig. 5: Capacity utilization

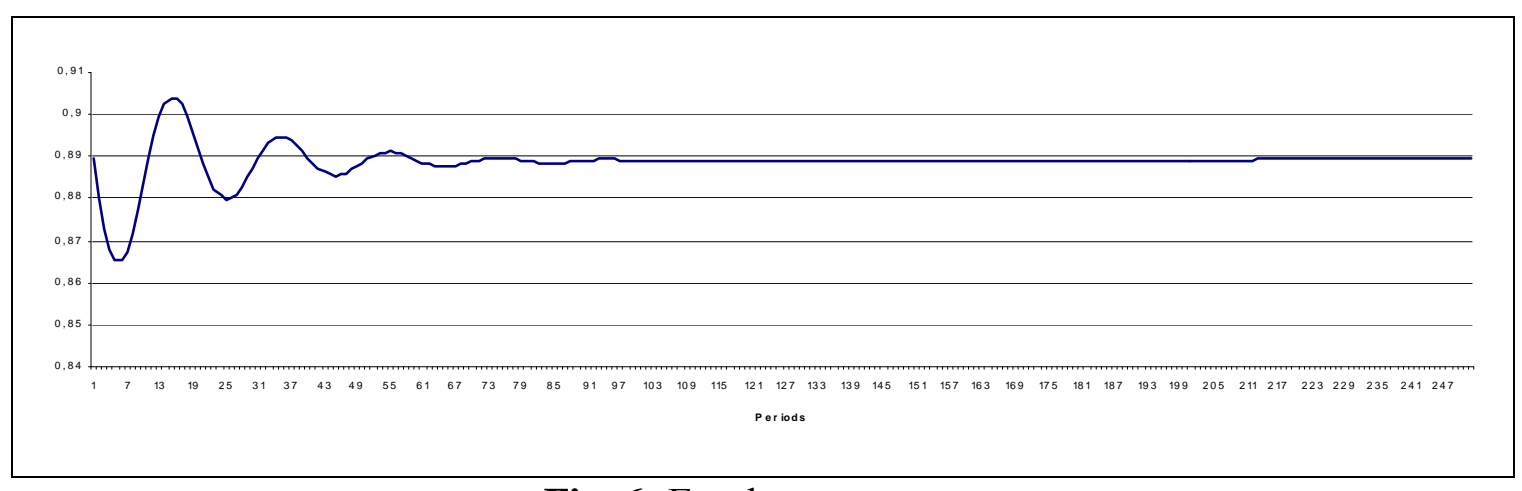

Fig. 6: Employment rate 


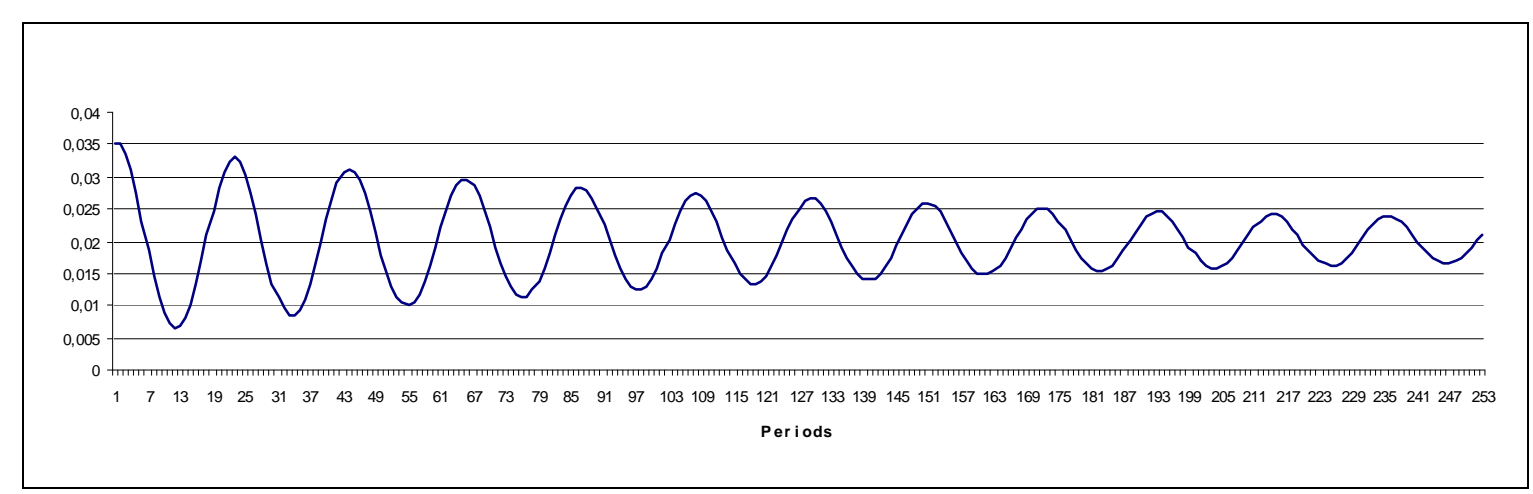

Fig. 7: Inflation rate

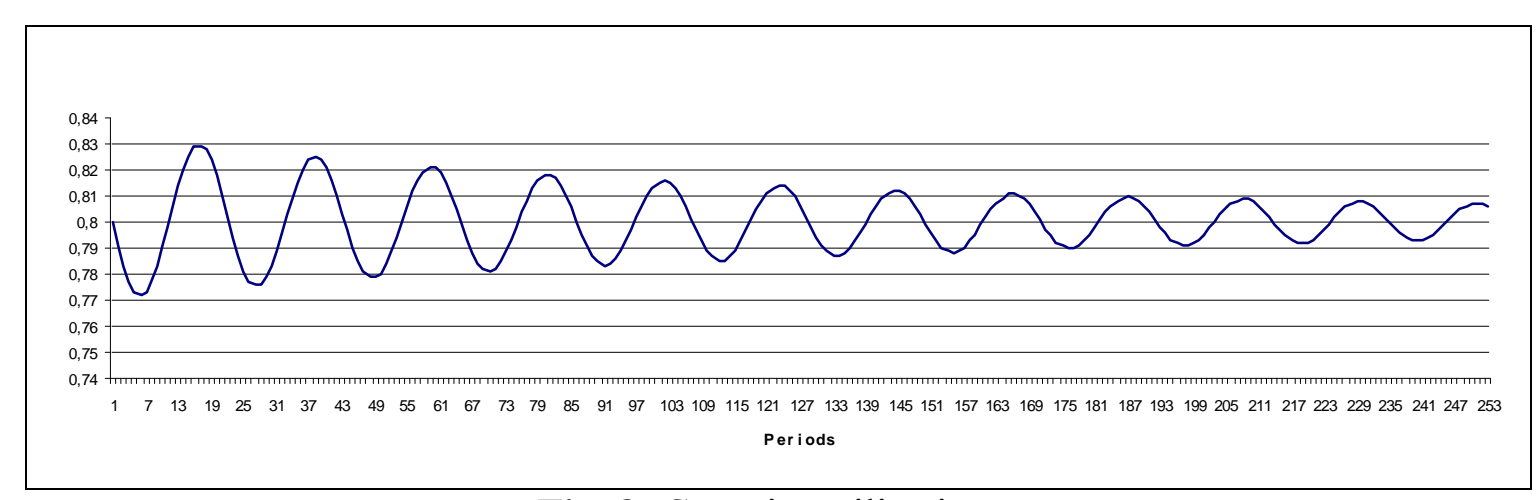

Fig. 8: Capacity utilization

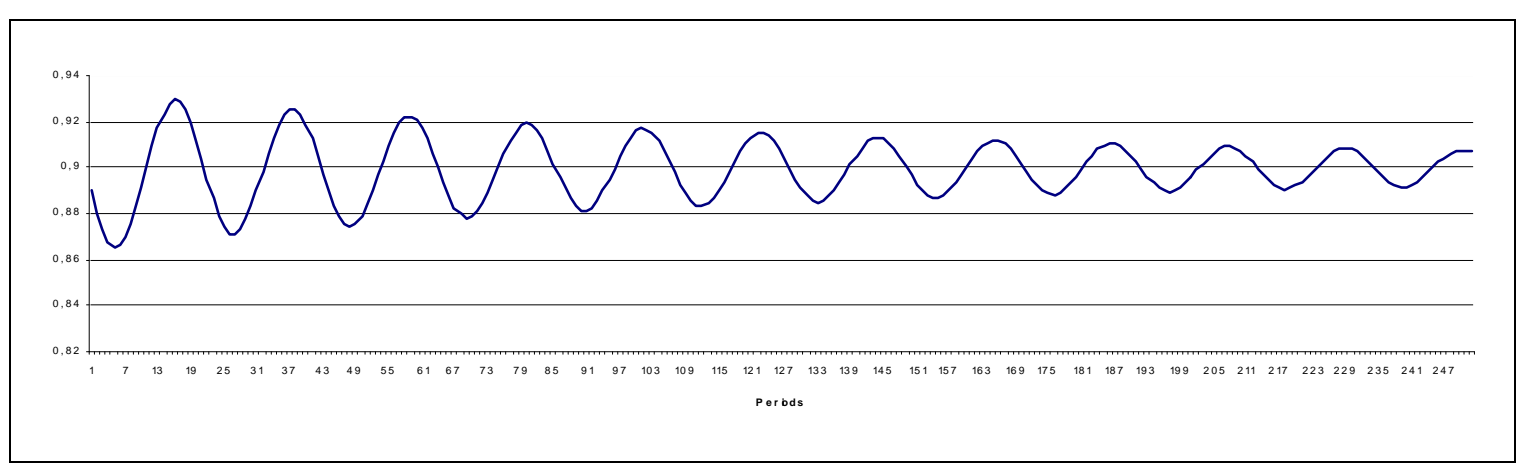

Fig. 9: Employment rate

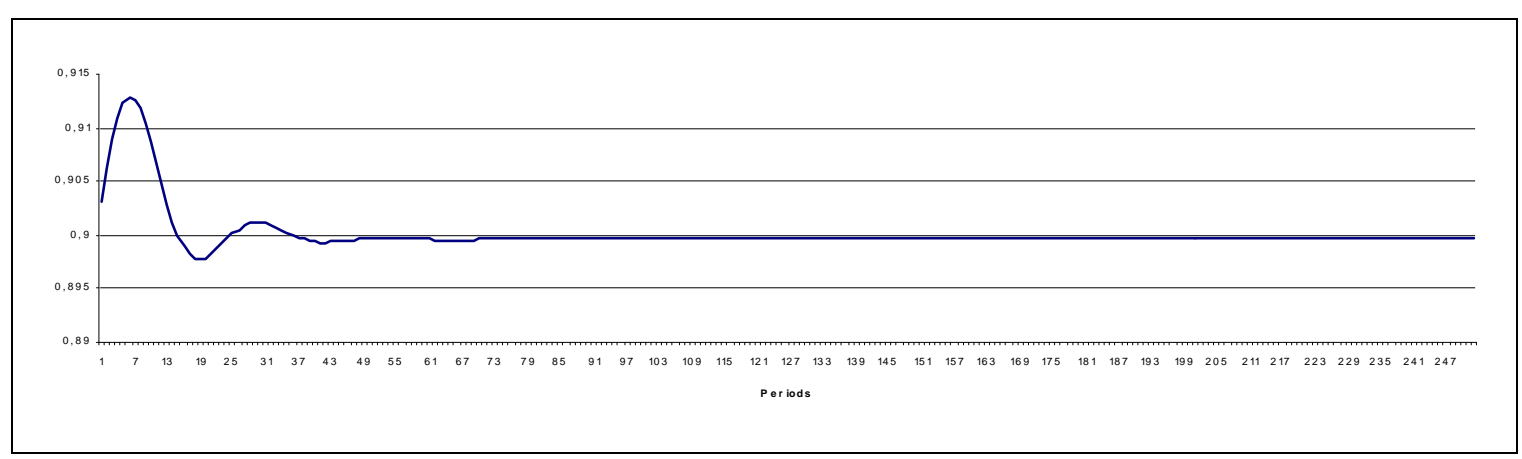

Fig. 10: Employment rate 


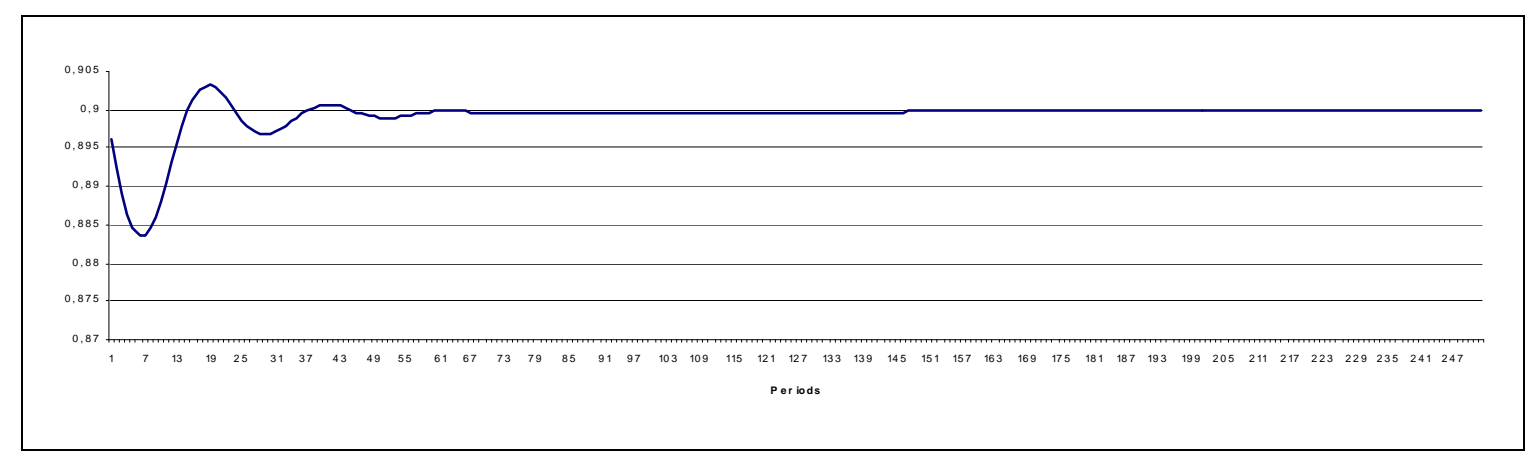

Fig. 11: Employment rate

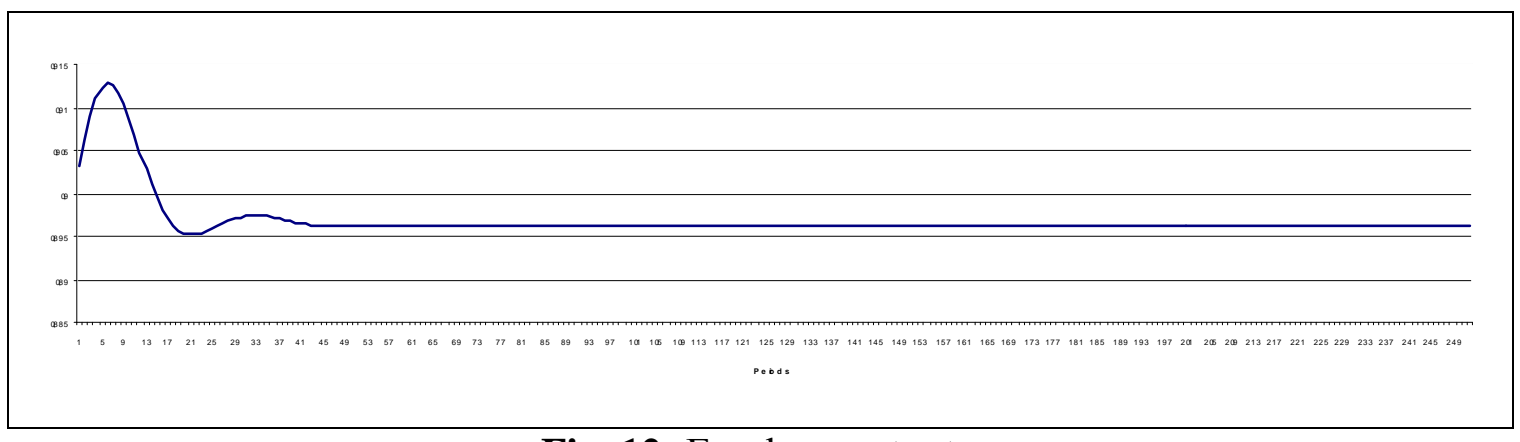

Fig. 12: Employment rate

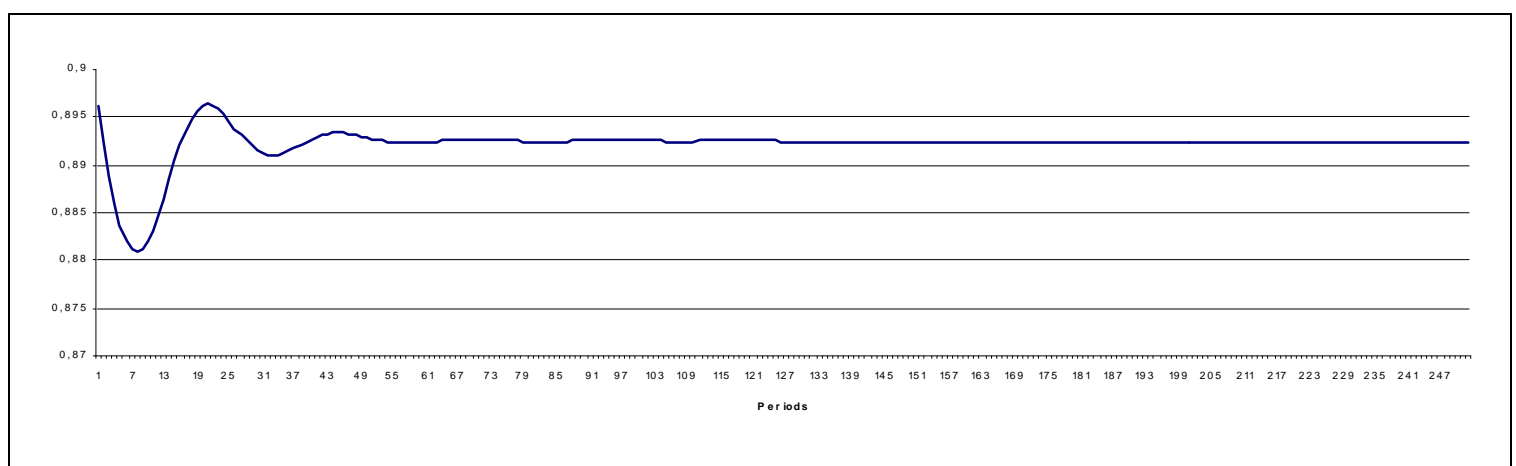

Fig. 13: Employment rate

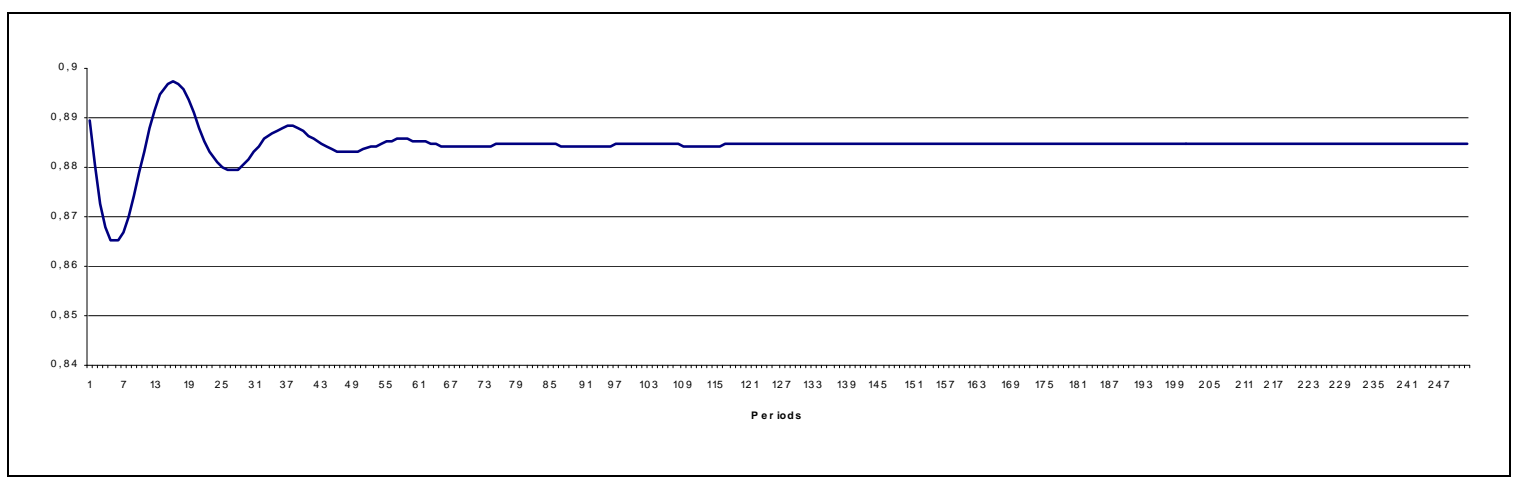

Fig. 14: Employment rate 


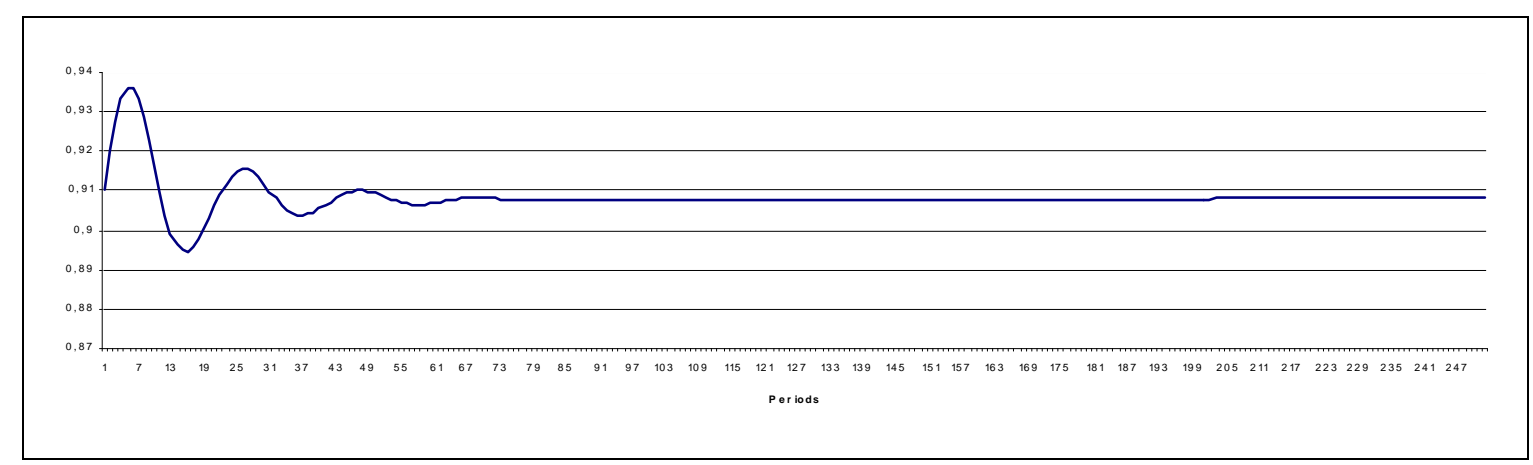

Fig. 15: Employment rate

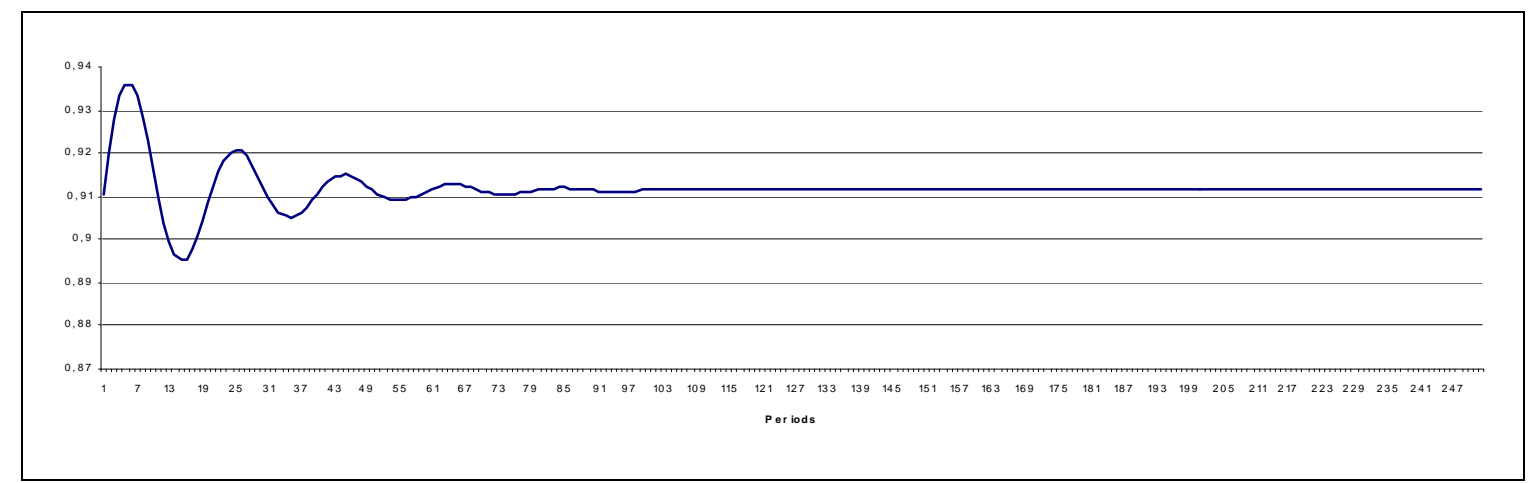

Fig. 16: Employment rate

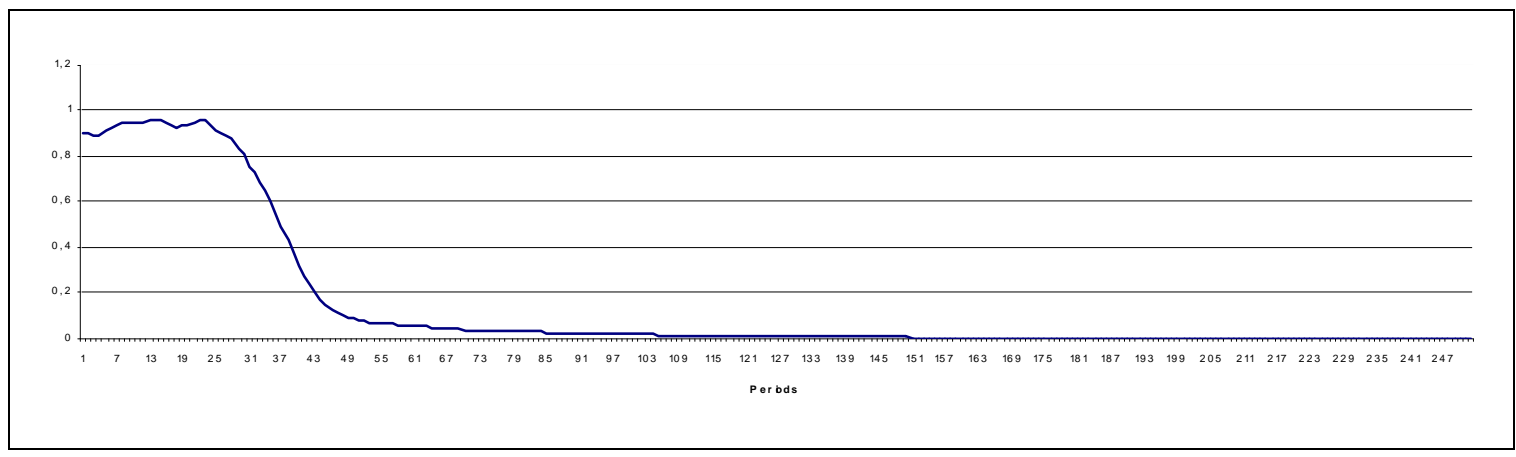

Fig. 17: Employment rate

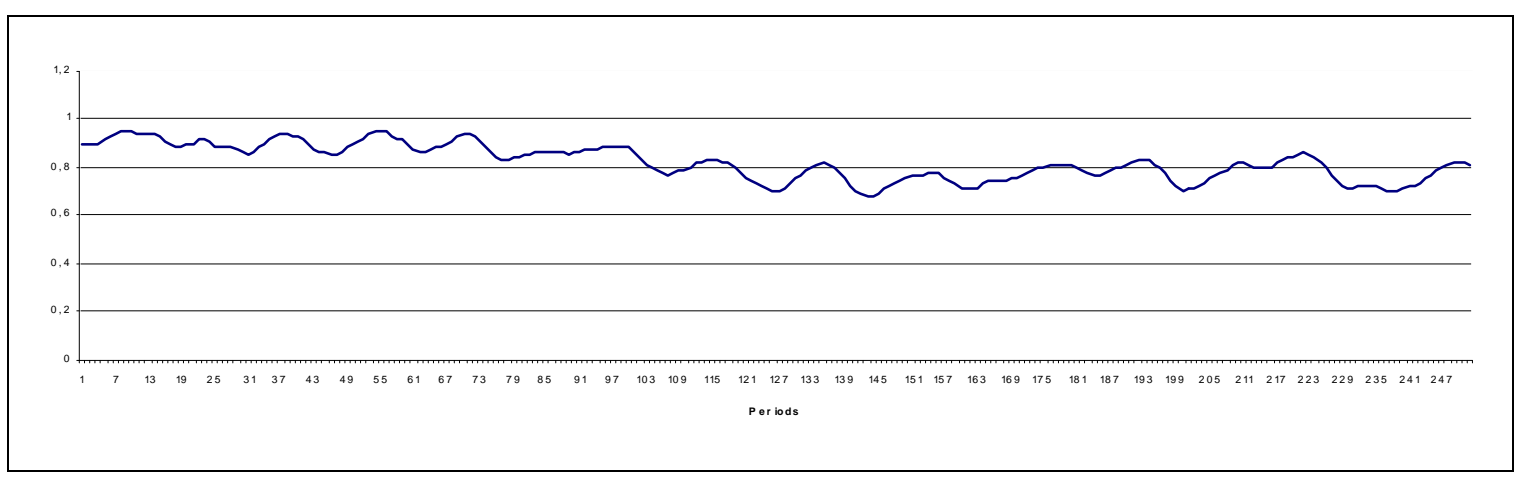

Fig. 18: Employment rate 


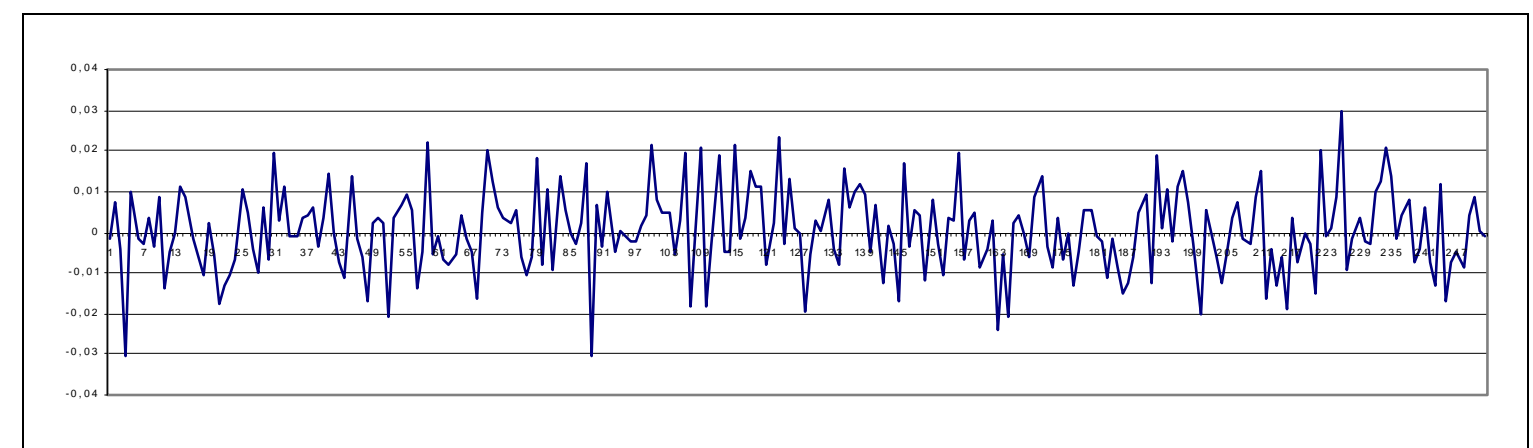

Fig. 19: Supply shocks

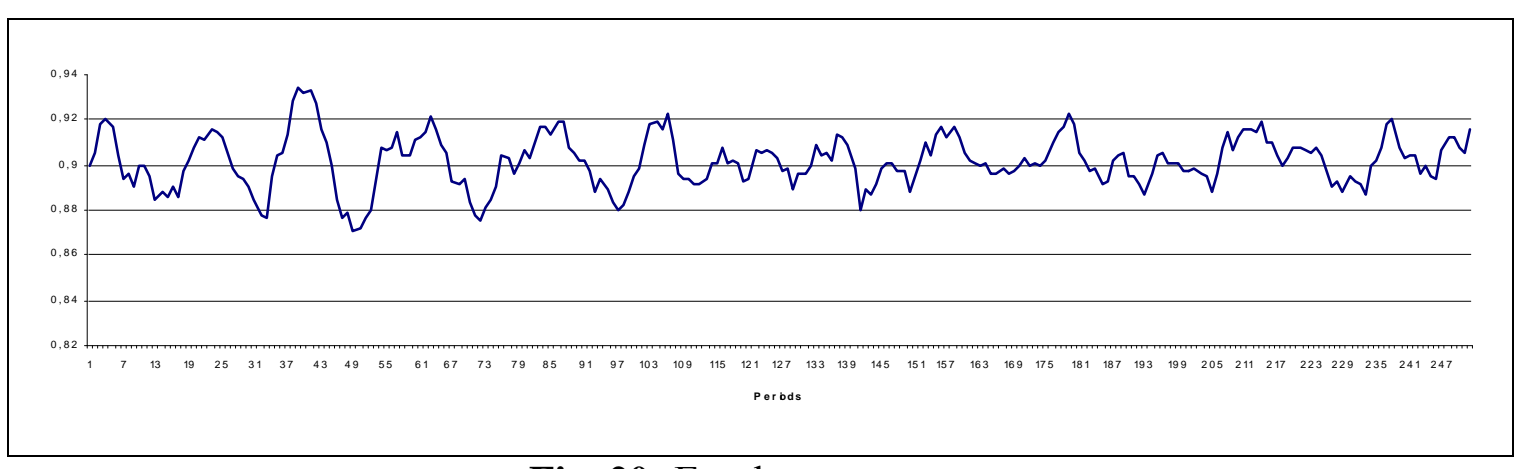

Fig. 20: Employment rate

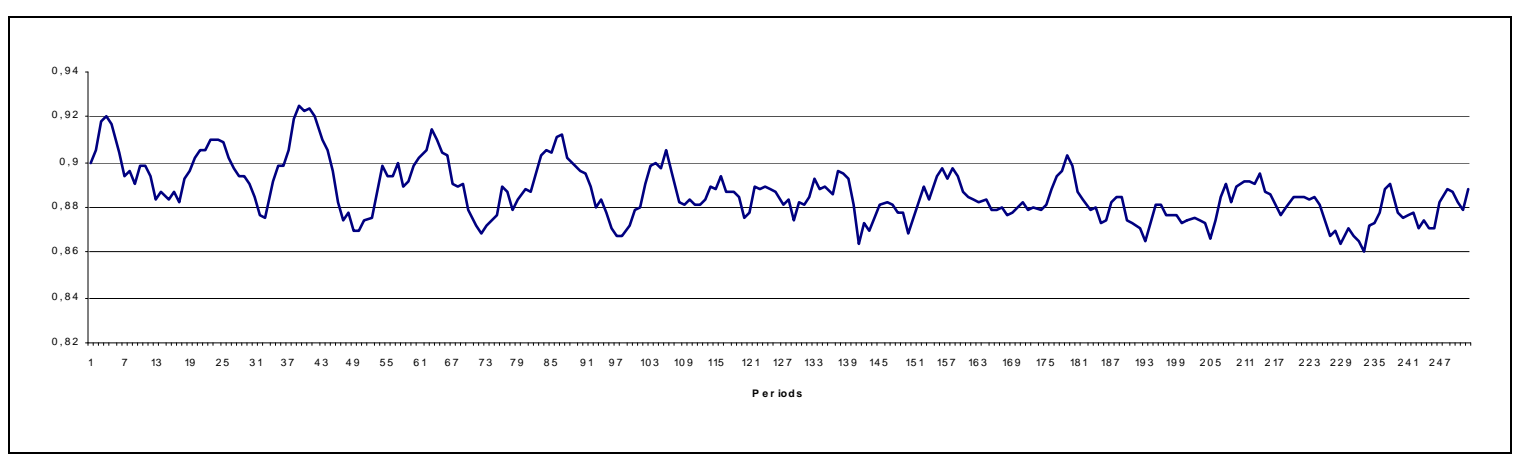

Fig. 21: Employment rate

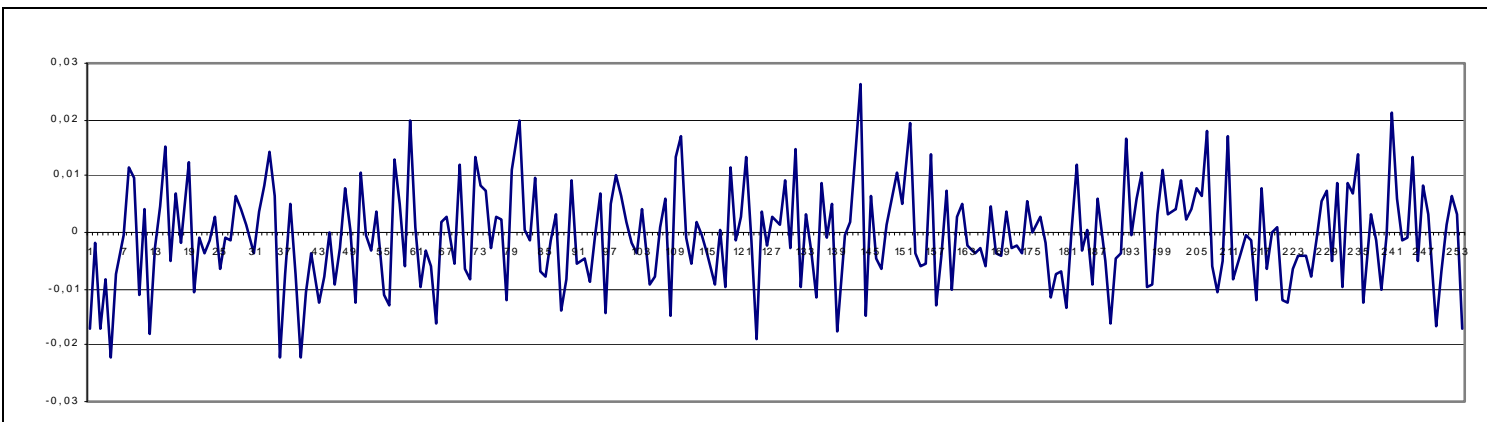

Fig. 22: Demand shocks

\section{References}

Agell, J. and Lundburg, P. 2003. Survey Evidence on Wage Rigidity: Sweden in the 1990s, Scandinavian Journal of Economics, 105(1), pp. 15-29. 
Akerlof, G.A., Dickens, W.T. and Perry, G.L. 1996. The Macroeconomics of Low Inflation, Brookings Papers in Economic Activity, 1, pp. 1-59.

Akerlof, G. A. 2007. The Missing Motivation in Macroeconomics, American Economics Review, 97(1), pp. 5-36.

Amable, B. Henry, J., Lordon, F. and Topol, R. 1995. Hysteresis revisited: a methodological approach, in Cross, R. (ed.) The Natural Rate of Unemployment: Reflections on 25 Years of the Hypothesis, Cambridge: Cambridge University Press, pp. 153-79.

Archibald, J. and Hunter, L. 2001. What is the Neutral Real Interest Rate, and How Can We Use It?, Reserve Bank of New Zealand Bulletin, 64(3), pp. 15-28.

Arestis, P. and Sawyer, M.C. 2006. The Nature and Role of Monetary Policy when Money is Endogenous, Cambridge Journal of Economics, 30(6), pp. 847-60.

Arestis, P. and Sawyer, M.C. 2008. A critical reconsideration of the foundations of monetary policy in the new consensus macroeconomic framework, Cambridge Journal of Economics, 32(5), pp. 761-779.

Asimakopulos, A. 1975. A Kaleckian Theory of Income Distribution, Canadian Journal of Economics, 8(3), August, pp. 313-333.

Ball, L. 1999. Aggregate Demand and Long-Run Unemployment, Brookings Papers on Economic Activity, 2, pp. 189-236.

Bernanke, B.S. and Reinhart, V. R. 2004. Conducting Monetary Policy at Very Low Short-term Interest Rates, American Economic Review, Papers and Proceedings, 94(2), May, pp. 85-90.

Bewley, T. F. 1999. Why Wages Do Not Fall During a Recession?, Cambridge, MA, Harvard University Press.

Bhaduri, A. and Marglin, S. 1990. Unemployment and the Real Wage: The Economic Basis for Contesting Political Ideologies, Cambridge Journal of Economics, 14, pp. 375-93.

Blinder, A.S. 2000. Monetary Policy at the Zero Lower Bound: Balancing the Risks, Journal of Money, Credit and Banking, 32(4), November, pp. 1093-1099.

Blinder, A.S. 2006. Monetary Policy Today: Sixteen Questions and about Twelve Answers, CEPS Working Paper No. 129, July. 
Bowles, S. and Boyer, R. 1995. Wages, aggregate demand, and employment in an open economy: an empirical investigation, in G. Epstein and H. Gintis (eds.) Macroeconomic policy after the conservative era: Studies in investment, saving and finance. Cambridge: Cambridge University Press.

Card, D. and Hyslop, D. 1996. Does Inflation "Grease the Wheels" of the Labor Market?, NBER, Working Paper 5538.

Carlin, W. and Soskice, D. 2005. The 3-Equation New Keynesian Model - A Graphical Exposition, Contributions to Macroeconomics, 5(1), Article 13.

Cassel, G. 1928. The Rate of Interest, the Bank Rate, and the Stabilization of Prices, Quarterly Journal of Economics, 42(4), August, pp. 511-529.

Clarida, R., Galí, J. and Gertler, M. 1999. The Science of Monetary Policy: A New Keynesian Perspective, Journal of Economic Literature, 37, December, pp. 1661-1707.

Corrado, C. and Mattey, J. 1997. Capacity Utilization, Journal of Economic Perspectives, 11(1), Winter, pp. 151-67.

Davidson, P. 1991. Is Probability Theory Relevant for Uncertainty?. A Post Keynesian Perspective, Journal of Economic Perspectives, 5(1), pp. 129-143.

De Veirman, E. 2007. Which Nonlinearity in the Phillips Curve?. The Absence of Accelerating Deflation in Japan, Reserve Bank of New Zealand Discussion Paper Series no. $2007 / 14$.

Dutt, A. K. 1997. Equilibrium, Path Dependence and Hysteresis in Post-Keynesian Models, in P. Arestis, G. Palma and M.C. Sawyer (eds.), Capital Controversy, Post Keynesian Economics and the Hystory of Economic Thought: Essays in Honour of Geoff Harcourt, pp. 238-253, London: Routledge.

Fehr, E. and Lorenz, G. 2005. The Robustness and Real Consequences of Nominal Wage Rigidity, Journal of Monetary Economics, 52(4), pp. 779-804.

Fontana, G. and Palacio-Vera, A. 2007. Are Long-run Price Stability and Short-run Output Stabilization All that Monetary Policy Can Aim For?, Metroeconomica, 58(2), pp. 269-298.

Fuhrer, J.C. and Madigan, B. F. 1997. Monetary Policy When Interest Rates are Bounded at Zero, Review of Economics and Statistics, 79(4), November, pp. 573-585. 
Gandolfo, G. 1997. Economic Dynamics, Springer-Verlag, Berlin.

Gantmacher, F.R. 1954. Theory of Matrices, Interscience Publishers, New York.

Garner, A. 1994. Capacity Utilization and U.S. Inflation, Federal Reserve Bank of Kansas City, Fourth Quarter, pp. 5-21.

Giavazzi, F. and Wyplosz, C. 1985. The Zero Root Problem: A Note on the Dynamic Determination of the Stationary Equilibrium in Linear Models, Review of Economic Studies, 52(2), pp. 353-57.

Gordon, D. 1995. Putting the horse (back) before the cart: disentangling the macro relationship between investment and saving, in G. Epstein and H. Gintis (eds.) Macroeconomic policy after the conservative era: Studies in investment, saving and finance. Cambridge: Cambridge University Press.

Greenwald, B.C. and Stiglitz, J.E. 1993. New and Old Keynesians, Journal of Economic Perspectives, 7(1), Winter, pp. 23-44.

Grosehn E.L. and Schweitzer, M. E. 1999. Identifying Inflation's Grease and Sand Effect in the Labor Market, in M. Feldstein (ed.) The Cost and Benefit of Price Stability, Chicago: Chicago University Press.

Harcourt, G. 1969. Some Cambridge Controversies in the Theory of Capital, Journal of Economic Literature, 7(2), pp. 369-405.

Hargreaves Heap, S.P. 1980. Choosing the Wrong 'Natural' Rate: Accelerating Inflation or Decelerating Employment and Growth, Economic Journal, 90(359), pp. 611-20.

Hein, E. and Ochsen, C. 2003. Regimes of interest rates, income shares, savings, and investment: a Kaleckian model and empirical estimations for some advanced OECDeconomies, Metroeconomica, 54(4), pp. 404-433.

Hein, E. and Vogel, L. 2008. Distribution and growth reconsidered: empirical results for six OECD countries, Cambridge Journal of Economics, 32(3), pp. 479-512.

Hicks, J. 1965. Capital and growth. Oxford: Oxford University Press. 
Holden, S. 2004. The Cost of Price Stability: Downward Nominal Wage Rigidity in Europe, Economica, 71(282), pp. 183-208.

Holden, S. and Wulfsberg, F. 2008. Downward Nominal Wage Rigidity in the OECD, The B.E. Journal of Macroeconomics, 8(1), Article 15.

Kaldor, N. 1939. Speculation and Economic Stability, Review of Economic Studies, 7(1), pp. 1-27.

Keynes, J. M. 1936. The General Theory of Employment, Interest and Money, Cambridge, Macmillan.

Keynes, J. M. 1937. The General Theory of Employment, Quarterly Journal of Economics, 51(2), pp. 209-223.

Krugman, P. 1998. It's Baaack: Japan's Slump and the Return of the Liquidity Trap, Brookings Papers on Economic Activity, 2, pp. 137-205.

Lavoie, M. 1996. Horizontalism, Structuralism, Liquidity Preference and the Principle of Increasing Risk, Scottish Journal of Political Economy, 43(3), August, pp. 275-300.

Lebow, D.E., Saks, R.E. and Wilson, B.A. 2003. Downward Nominal Wage Rigidity: Evidence from the Employment Cost Index, Advances in Macroeconomics, 3(1), Art.2.

León-Ledesma, M. A. 2002. Unemployment Hysteresis in the US States and the EU: A Panel Approach, Bulletin of Economic Research, 54(2), pp. 95-103.

Lindbeck, A. 1993. Unemployment and Macroeconomics, Cambridge, MA: MIT Press.

Logeay, C. and Tober, S. 2006. Hysteresis and the NAIRU in the Euro Area, Scottish Journal of Political Economy, 53(4), pp. 409-429.

Marglin, S.A. 1984. Growth, Distribution and Prices, Cambridge (MA): Harvard University Press.

McElhattan, R. 1985. Inflation, Supply Shocks and the Stable-Inflation Rate of Capacity Utilization, Federal Reserve Bank of San Francisco Economic Review, 1, pp. 45-63. 
Meyer, L.H. 2001. Does Money Matter?, Federal Reserve Bank of St. Louis Review, September/October, pp. 1-15.

Mourougane, A. and Ibaragi, H. 2004. Is There a Change in the Trade-off Between Output and Inflation at Low or Stable Inflation Rates?. Some Evidence in the Case of Japan, Economics Department Working Paper No. 379, OECD.

Myrdal, G. 1939. Monetary Equilibrium, London: W. Hodge.

Naastepad, R. and Storm, S. 2006/07. OECD demand regimes (1960-2000), Journal of Post Keynesian Economics, 29(2), pp. 213-248.

Naastepad, R. 2006. Technology, demand and distribution: a cumulative growth model with an application to the Dutch productivity slowdown, Cambridge Journal of Economics, 30(3), pp. 403-434.

Orphanides, A. and Wieland, V. 2000. Inflation zone targeting, European Economic Review, 44, pp. 1351-1387.

Palley, T.I. 1994. Escalators and Elevators: A Phillip Curve for Keynesians, Scandinavian Journal of Economics, 96(1), pp. 111-116.

Peltzman, S. 2000. Prices Rise Faster than They Fall, Journal of Political Economy, 108(3), pp. 466-502.

Pollin, R. 1985. Stability and Instability in the Debt-Income Relationship, American Economic Review, Papers and Proceedings, 75(2), May, pp. 344-350.

Reifschneider, D. and Williams, J.C. 2000. Three Lessons for Monetary Policy in a Low-Inflation Era, Journal of Money, Credit and Banking, 32(4), pp. 936-966.

Røed, K. 1997. Hysteresis in unemployment, Journal of Economic Surveys, 11(4), pp. 389-418.

Rowthorn, R. 1977. Conflict, inflation and Money, Cambridge Journal of Economics, 1, pp. 215-39.

Sawyer, M.C. 1982. Collective Bargaining, Oligopoly and Macro-Economics, Oxford Economic Papers, 34(3), pp. 428-48. 
Setterfield, M. 1998. Adjustment Asymmetries and Hysteresis in Simple Dynamic Models, Manchester School, 66(3), pp. 283-301.

Skott, P. 1989. Conflict and Effective Demand in Economic Growth, Cambridge University Press.

Spence, A.M. 1977. Entry, Capacity, Investment and Oligopolistic Pricing, Bell Journal of Economics, 8(2), Autumn, pp. 534-44.

Stockhammer, E. 2008. Is the NAIRU Theory a Monetarist, New Keynesian, Post Keynesian or a Marxist Theory?, Metroeconomica, 59(3), pp. 479-510.

Stockhammer, E. and Onaran, Ó. 2004. Accumulation, Distribution and Employment: A Structural VAR Approach to a Kaleckian Macro-model, Structural Change and Economic Dynamics, 15(4), pp. 421-47.

Stockhammer, E., Onaran, Ó. and Ederer, S. 2007. Functional income distribution and aggregate demand in the Euro-area, Vienna University of Economics \& B.A Department of Economics Working Paper no. 102.

Taylor, J.B. 1993. Discretion Versus Policy Rules in Practice, Carnegie-Rochester Conference Series on Public Policy, 39, pp. 195-214.

Ueda, K. 2000. Japan's Experience with Zero Interest Rates, Journal of Money, Credit and Banking, 32(4), November, pp. 1107-1109.

Weber, A.A., Lemke, W. and Worms, A. 2008. How useful is the concept of the natural real rate of interest for monetary policy?, Cambridge Journal of Economics, 32(1), pp. 49-63.

Wicksell, K. 1936[1898]. Interest and Prices: a study of the causes regulating the value of money, London: Macmillan.

Woodford, M. 2003. Interest and Prices: Foundations of a Theory of Monetary Policy, Princeton, NJ, Princeton University Press.

Yates, T. 2002. Monetary Policy and the Zero Bound to Interest Rates: A Review, Working paper No. 190, October, European Central Bank. 
* E-mail: apv@ccee.ucm.es. Correspondence address: Alfonso Palacio-Vera, Departamento de Economía Aplicada III, Facultad de Ciencias Económicas y Empresariales, Campus de Somosaguas, Universidad Complutense de Madrid, Pozuelo de Alarcón, 28223 (Madrid), Spain. Acknowledgements: the author would like to thank Engelbert Stockhammer as well as to participants in the $5^{\text {th }}$ International Conference "Developments in Economic Theory and Policy" held at the University of the Basque Country in Bilbao (Spain) in July 2008 for their comments and suggestions on a previous draft of this paper. Of course, the usual disclaimer applies.

${ }^{1}$ Examples of the rapidly growing empirical literature on this topic are the studies by Bowles and Boyer (1995), Gordon (1995), Hein and Ochsen (2003), Stockhammer and Onaran (2004), Naastepad (2006), Naastepad and Storm (2006/07), Hein and Vogel (2007) and Stockhammer et al. (2007).

2 Detailed expositions of the NC approach can be found in Clarida et al. (1999) and Meyer (2001) and two recent critical reviews are in Arestis and Sawyer (2006, 2008).

${ }^{3}$ In this respect, Krugman (1998) argues that the negative output-gap the Japanese economy exhibited in the late 1990s was largely underestimated in official statistics. He adds that it could have been as large as 8 per cent of GDP and it may have grown much larger since 1998.

${ }^{4}$ For instance, Mourougane and Ibaragi (2004) estimate Phillips curves for Japan and find evidence that at low or negative inflation rates, indicators of demand pressure have no statistically significant effect on price inflation.

${ }^{5}$ Of course, current output may also fall short of potential output if the CB purposively sets the real interest rate above the neutral real interest rate in order to trigger a disinflation process. Thus, by an aggregate demand deficiency we mean a situation where the CB cannot make current output equal to potential even if the short-term nominal interest rate is equal to zero.

${ }^{6}$ This definition of the neutral interest rate differs from Keynes' (1936, p. 243) one in that he views the former as the long-term interest rate that yields full-employment whereas we define it as the long-term interest rate that yields an employment rate that keeps inflation constant.

${ }^{7}$ We thus believe, as Keynes (1936, p. 173), that between monetary policy and economic activity 'there may be several slips between the cup and the lip'.

${ }^{8}$ For this particular example we assume "constant relative risk aversion" preferences of the representative household and that the utility of each future generation is weighted equally irrespective of size.

${ }^{9}$ The classical presentation of the notion of the natural interest rate is in Wicksell (1936[1898]).

${ }^{10}$ This third meaning is emphasized in Cassel (1928).

${ }^{11}$ This feature of PK theory is emphasized in Stockhammer (2007). He notes that 'as a theory of inflation the NAIRU model resembles the conflict inflation theory of Post Keynesian origin. This theory... reflects Post Keynesians long-standing conviction that inflation is the outcome of distributional conflict (and not excessive growth in the money supply) and thus has to be combated through incomes policies' (Stockhammer, 2008, p. 495).

12 The non-accelerating inflation rate of unemployment or NAIRU is hence equal to $1-\bar{e}$. In this study, we assume that the CIER is equivalent to the notion of "equilibrium unemployment". The latter refers to a rate of unemployment that is determined at the intersection of a price-setting function and an upwardsloping wage-setting function in real wage-employment space. Admittedly, a substantive difference between these two concepts is that the NAIRU is typically defined as a situation where the rate of inflation is constant, whereas the only requirement of the concept of "equilibrium unemployment" is that real wages are constant (when there is no productivity growth) or else grow at the same pace than productivity. Yet, the two approaches can be reconciled by grafting money wage and price dynamics onto the static approach (see Lindbeck, 1993, Appendix B), 
${ }^{13}$ In terms of the concept of "equilibrium unemployment" alluded to above, a rise in $m$ will lead to a leftward shift in the price-setting curve and, hence, to a higher rate of "equilibrium unemployment".

${ }^{14}$ Evidence for AID is provided in Peltzman (2000). Unlike in a perfectly competitive economy, in an imperfectly competitive one the price-setting curve may not be negatively-sloped so that, for the relevant range of the curve, there may be a neutral or even a positive relationship between the employment rate and the real (product) wage. The former implies that, in the presence of DMWR, an increase in the real (product) wage paid by the firms once the actual inflation rate is low or negative may not necessarily result in a higher level of "equilibrium unemployment".

${ }^{15}$ Hence, the long-term real interest rate exhibits an upper bound equal to $\mu-\left(\phi_{\pi} \pi^{C R}-\phi_{U}\right) / \phi_{\pi}$ whenever the short-term nominal interest rate is zero and the inflation rate becomes negative.

${ }^{16}$ A pertinent rebuttal to the official position is in Greenwald and Stiglitz (1993) who, referring to the "real balance" effect, point out that "quantitatively, it is surely an $n$th order effect; one calculation put it that, even at the fastest rate at which prices fell in the Great Depression, it would take more than two centuries to restore the economy to full employment. And in the short run even its sign is ambiguous, as inter-temporal substitution effects may (depending on expectations) more than offset the wealth effects' (Greenwald and Stiglitz, 1993, p.36).

${ }^{17}$ In general, an asterisk denotes the steady growth value of the variable. However, in the case of $u$ its steady growth value coincides with the desired rate of capacity utilization. Likewise, the target inflation rate coincides with the steady growth value of the inflation rate.

${ }^{18}$ An interest rate policy rule like this one can be easily derived from a loss function according to which the CB seeks to minimize the deviation of the actual inflation rate and actual level of output from their respective target levels (see, for instance, Carlin and Soskice, 2005).

${ }^{19}$ Henceforth, an "inflation shock" is a shock to the inflation rate that does not affect the CIER.

${ }^{20}$ In this study we assume that the CB estimates the steady growth neutral interest rate correctly in order to frame our results in the most favourable scenario for the implementation of monetary policy decisions. Of course, we readily admit that any CB faces enormous practical difficulties when estimating it (see, for instance, Weber et al., 2008).

${ }^{21}$ Let us note that, for the sake of simplicity, we assume that $S_{m}=0$.

${ }^{22}$ See the Routh-Hurwitz conditions for the stability of dynamical systems in Gandolfo (1997, pp. 21923). 